Article

\title{
Evaluating the SEVIRI Fire Thermal Anomaly Detection Algorithm across the Central African Republic Using the MODIS Active Fire Product
}

\author{
Patrick H. Freeborn ${ }^{1}{ }^{*}$, Martin J. Wooster ${ }^{2,3}$, Gareth Roberts ${ }^{4}$ and Weidong Xu ${ }^{5}$ \\ 1 Geographic Information Science Center of Excellence, South Dakota State University, \\ Brookings, SD 57007, USA \\ 2 King's College London, Earth and Environmental Dynamics Research Group, Department of \\ Geography, London WC2R 2LS, UK; E-Mail: martin.wooster@kcl.ac.uk \\ 3 NERC National Centre for Earth Observation, UK \\ 4 Geography and Environment, University of Southampton, Highfield, Southampton SO17 1BJ, UK; \\ E-Mail: G.J.Roberts@ soton.ac.uk \\ 5 Plymouth Marine Laboratory, Prospect Place, Plymouth PL1 3DH, UK; E-Mail: wexu@pml.ac.uk \\ * Author to whom correspondence should be addressed; E-Mail: patrick.freeborn@sdstate.edu; \\ Tel.: +1-605-688-4787; Fax: +1-605-688-5227.
}

Received: 27 December 2013; in revised form: 18 February 2014 / Accepted: 24 February 2014 / Published: 28 February 2014

\begin{abstract}
Satellite-based remote sensing of active fires is the only practical way to consistently and continuously monitor diurnal fluctuations in biomass burning from regional, to continental, to global scales. Failure to understand, quantify, and communicate the performance of an active fire detection algorithm, however, can lead to improper interpretations of the spatiotemporal distribution of biomass burning, and flawed estimates of fuel consumption and trace gas and aerosol emissions. This work evaluates the performance of the Spinning Enhanced Visible and Infrared Imager (SEVIRI) Fire Thermal Anomaly (FTA) detection algorithm using seven months of active fire pixels detected by the Moderate Resolution Imaging Spectroradiometer (MODIS) across the Central African Republic (CAR). Results indicate that the omission rate of the SEVIRI FTA detection algorithm relative to MODIS varies spatially across the CAR, ranging from $25 \%$ in the south to $74 \%$ in the east. In the absence of confounding artifacts such as sunglint, uncertainties in the background thermal characterization, and cloud cover, the regional variation in SEVIRI's omission rate can be attributed to a coupling between SEVIRI's low spatial resolution detection bias (i.e., the inability to detect fires below a
\end{abstract}


certain size and intensity) and a strong geographic gradient in active fire characteristics across the CAR. SEVIRI's commission rate relative to MODIS increases from $9 \%$ when evaluated near MODIS nadir to 53\% near the MODIS scene edges, indicating that SEVIRI errors of commission at the MODIS scene edges may not be false alarms but rather true fires that MODIS failed to detect as a result of larger pixel sizes at extreme MODIS scan angles. Results from this work are expected to facilitate (i) future improvements to the SEVIRI FTA detection algorithm; (ii) the assimilation of the SEVIRI and MODIS active fire products; and (iii) the potential inclusion of SEVIRI into a network of geostationary sensors designed to achieve global diurnal active fire monitoring.

Keywords: validation; SEVIRI; geostationary active fire detection algorithm; MODIS

\section{Introduction}

The ignition and propagation of landscape fires burning across Africa follows the diurnal cycle of local weather [1]. Savanna fires are typically lit earlier in the day [2], and as the day progresses, hotter and drier conditions in the afternoon promote faster fire spread rates, longer active fire perimeters, and increased fireline intensities [3]. After the mid-day peak in optimum burning conditions, air temperature decreases, relative humidity increases, and fire behaviour subsides. Whilst smaller agricultural and pastoral fires tend to extinguish during the evening [4], many uncontrolled fires burning across Africa's uninterrupted landscapes persist well into the night [2].

Satellite-based remote sensing of active fires is perhaps the only practical way to consistently monitor diurnal fluctuations in fire behavior at regional to continental scales [5]. At present, however, polar-orbiting sensors only observe ground locations along the equator up to four times daily. Consequently fires with lifetimes shorter than the overpass return interval of a polar-orbiting sensor may remain undetected. Even if a fire is detected by a polar-orbiting sensor, the overpass schedule coupled with variations in sensor scan angle will inevitably limit and confound a reconstruction of the fire's diurnal cycle [6,7]. Although several methods have been developed to overcome the inability of a polar orbiting sensor to characterize the full diurnal cycle of fire activity (e.g., [8-11]) these techniques require the accumulation of active fire pixels into large spatiotemporal windows to produce "aggregate" or "average" diurnal cycles representative of broad geographical regions and entire fire seasons. Although such generalized diurnal cycles of fire activity may be indicative of synoptic scale land use practices and meteorology, an "aggregate" or "average" diurnal cycle may not represent any particular event since fires at finer spatiotemporal resolutions are increasingly influenced by the actual timing of ignition and the local weather conditions.

In contrast, geostationary sensors offer identical views of the same ground location at high repetition rates and therefore (i) offer more opportunities to detect and characterize fires that may not have been burning (or burning as vigorously) at the overpass time of a polar-orbiting sensor (e.g., [12]); and (ii) are more amenable for directly measuring diurnal cycles of fire activity [13-15]. Nevertheless the ability of geostationary sensors to monitor diurnal cycles of fire activity is limited. Due to their much higher orbits, geostationary sensors typically have larger instantaneous geometric field of views 
(IGFOVs) than polar-orbiting sensors. A larger IGFOV subtends a larger ground area and effectively reduces the fraction of a pixel occupied by fire. This in turn diminishes the ability of a geostationary sensor to discriminate smaller and/or lower intensity fires from the non-fire surroundings (e.g., [16]). In addition to this "low spatial resolution detection bias", cloud cover also prohibits geostationary sensors from acquiring near-continuous observations of fire activity by either completely obscuring the land surface or, at the very least, confounding the background temperature statistics required to define contextual thresholds $[17,18]$.

Despite the aforementioned caveats of characterizing diurnal cycles of fire activity from geostationary sensors, modern applications are using high-frequency observations of active fire pixel counts [19], sub-pixel active fire area (e.g., [20]), and fire radiative power, FRP (e.g., [15,21]), to generate diurnal cycles of trace gas and aerosol emission fluxes (e.g., [22]) and smoke injection heights (e.g., [23,24]), which when input into atmospheric transport models can be used to forecast plume dispersion and air quality (e.g., [25,26]). As cautioned by Eva and Lambin [8], however, a failure to understand the accuracy and limitations of satellite-based fire products could lead to improper interpretations of the spatiotemporal pattern of biomass burning (e.g., [27,28]) and flawed estimates of fuel consumption and smoke production (e.g., [29,30]).

Given the operational and scientific attractiveness of monitoring diurnal cycles of fire activity, it is imperative that geostationary active fire detection algorithms be validated. Therefore, as part of an on-going effort to evaluate the performance of the Spinning Enhanced Visible and Infrared Imager (SEVIRI) Fire Thermal Anomaly (FTA) detection algorithm, this work compares near-simultaneous SEVIRI and Moderate Resolution Imaging Spectroradiometer (MODIS) observations of fire activity across the Central African Republic (CAR; Figure 1). In addition to quantifying SEVIRI's omission and commission rates relative to MODIS, this work examines the design features and observation conditions that influence the evaluation of the FTA detection algorithm.

\section{Datasets}

\subsection{The SEVIRI Active Fire Products}

Since 2008 the European Organisation for the Exploitation of Meteorological Satellites (EUMETSAT) Land Surface Analysis Satellite Applications Facility (LSA SAF) has been using the FTA detection algorithm to operationally generate the Meteosat SEVIRI FRP-PIXEL product every 15-min within four sub-continental windows covering Europe, northern Africa, southern Africa, and South America [31,32]. Each LSA SAF product is assigned a status as it evolves through its lifecycle, from "in development" during its inception to "operational" when it's mature. Whether a product is declared operational (after review by a steering group) depends on the assessment of several factors affecting the product quality, including, but not limited to, scientific and engineering validation efforts, related services (e.g., timeliness and dependability of delivery and archiving), and documentation (e.g., algorithm theoretical basis documents, product user manuals, and validation reports). 
Figure 1. Map of the Central African Republic (CAR) illustrating (a) the four regions of interest (ROIs) used herein and the GLC2000 landcover classes found within the ROIs. The geographical gradient of fire activity across the CAR is highlighted using the seasonal FRE measured by SEVIRI (b); the nighttime-to-daytime ratio of the FRE measured by SEVIRI (c); and (d) the maximum FRP measured by SEVIRI. Maps (b-d) were derived from all SEVIRI active fire pixels recorded in the operational FRP-PIXEL product between 1 October 2008 and 30 April 2009, and are presented in the native SEVIRI image coordinate system.
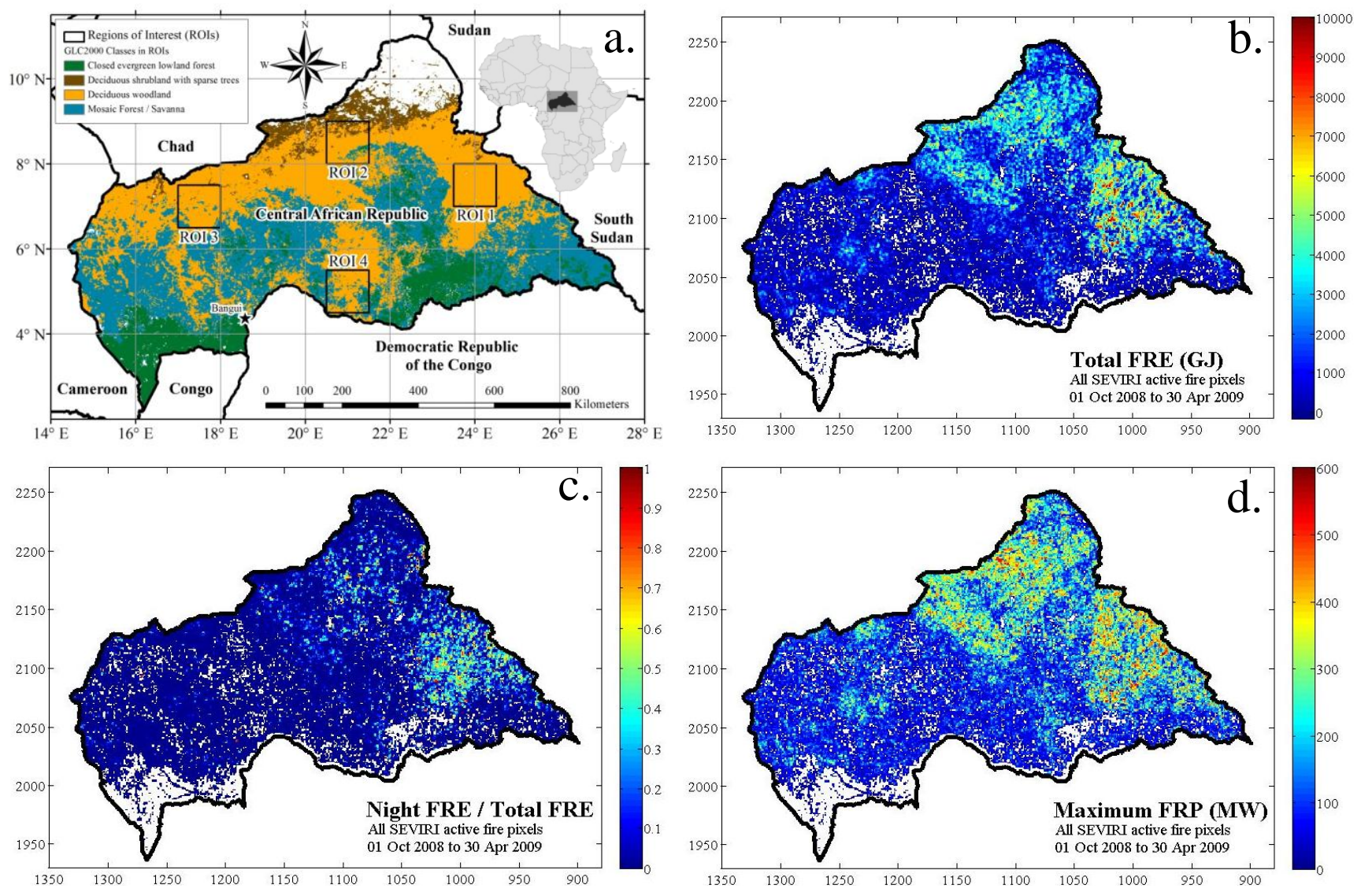

The FTA detection algorithm identifies SEVIRI pixels containing active fires based upon the detection strategies first developed by Roberts et al. [17] and refined by Roberts and Wooster [33]. After passing the detection stages, the fire radiative power emitted from each SEVIRI " $3 \mathrm{~km}$ " active fire pixel is calculated using the middle infrared (MIR) radiance method [34,35] and is corrected for atmospheric transmissivity, $\tau_{\text {atm }}$, using the 3-hourly total column water vapour (TCWV) fields produced by the European Centre for Medium Range Weather Forecasting, ECMWF [31]. Although the IGFOV of SEVIRI varies depending on view zenith angle (VZA), the use of the term " $3 \mathrm{~km}$ " here refers to SEVIRI's nominal ground sampling distance (GSD) between pixel centers at the sub-satellite point (SSP).

The operational FRP-PIXEL product is accessible via the LSA SAF website [36] and in near-real time on the EUMETCAST satellite data transmission system as a pair of Hierarchical Data Format (HDF) files. The "list file" contains amongst other information a record of the image acquisition time, geographic coordinates, and atmospherically corrected FRP associated with each SEVIRI active fire 
pixel [32]. The "quality file" is a mask with the same dimensions as a sub-continental window indicating the processing status of every SEVIRI thermal pixel [32]. Not all of the 12 original quality flags were relevant to this study so the classification scheme was condensed into the following seven categories: (i) fire pixel; (ii) non-potential fire pixel; (iii) pixel affected by sunglint or pixel where the test for sunglint failed; (iv) pixel without a defined background temperature; (v) potential fire pixel that could not be confirmed as a true fire pixel since it did not breach the contextual detection thresholds; (vi) pixel affected by clouds or cloud edges; and (vii) other.

\subsection{The MODIS Active Fire Products}

The MODIS Level 2 Collection 5 Active Fire Products (abbreviated MOD14 for Terra and MYD14 for Aqua) provide the most basic level of information about active fire pixels detected within a $2340 \mathrm{~km} \times 2030 \mathrm{~km}$ granule [37]. Absolute, multi-channel, and contextual detection thresholds are used to identify MODIS "1 km" fire pixels [38,39], and a single waveband approach is used to calculate the FRP emitted from each fire pixel [40,41]. Although the IGFOV of MODIS varies with scan angle [42], the use of the term " $1 \mathrm{~km}$ " here refers to the nominal GSD between MODIS pixel centers at nadir.

The MODIS fire pixel table and fire mask are consolidated into a single HDF file downloadable from NASA's Earth Observing System (EOS) Clearinghouse (ECHO) Reverb client [43]. The MOD/MYD14 fire pixel tables contain amongst other information a record of the observation time, geographic coordinates and FRP for each active fire pixel. The MODIS fire mask has the same dimensions as a granule (e.g., 1354 samples $\times 2030$ lines), and all pixels in the granule are assigned one of the following classes: (i) unprocessed; (ii) water; (iii) cloud; (iv) non-fire clear land; (v) unknown; or (vi) low-; (vii) nominal-; or (viii) high-confidence fire pixel [37].

\section{Selection of the Datasets and the CAR as a Study Site}

The decision to assess SEVIRI's active fire detection performance using the MODIS active fire products is based on four reasons. First, the near-nadir detection performance of MODIS Terra has been comprehensively validated over a global range of biomes, fire regimes, and atmospheric conditions using coincident 30 m Advanced Spaceborne Thermal Emission and Reflection Radiometer (ASTER) observations [16,44-46]. Second, the MODIS active fire products have previously been used to evaluate alternative SEVIRI active fire detection algorithms (e.g., [17,33,47,48]). If the same MODIS reference dataset is used to evaluate SEVIRI's detection performance, then different SEVIRI active fire detection algorithms can be more consistently and confidently compared with one another. Third, by evaluating SEVIRI against MODIS, results herein can be used to inform and facilitate the assimilation of the SEVIRI and MODIS active fire products, providing an opportunity to alleviate both SEVIRI's low spatial resolution detection bias as well as the $3 \mathrm{~h}$ and $9 \mathrm{~h}$ gaps between MODIS overpasses. And finally, using MODIS as the "needle" and the MOD/MYD14 active fire products as the "thread" may be the best possible way to "stitch" SEVIRI into a network of geostationary sensors designed to achieve near global diurnal fire monitoring [49].

The Central African Republic (CAR) was selected as a study site based on the criteria proposed in a joint venture between the Global Observation of Forest Cover (GOFC) Fire Implementation team and 
the Committee on Earth Observing Satellites (CEOS) Land Product Validation (LPV) subgroup [50]. First, a substantial amount of fire activity occurs in the CAR. According to burned area estimates by Giglio et al. [51], the Global Fire Emissions Database, GFEDv.3.1 [52], reports that biomass burning in the CAR accounted for between $19 \%$ and $29 \%$ of the annual pyrogenic carbon budget in the northern hemisphere of Africa, emitting on average $107 \mathrm{TgCyr}^{-1}$ between 1997 and 2010.

The CAR was also selected as a study site since it encompasses a strong geographical gradient of fire regimes and land use practices [53,54]. Massive fire fronts tens of kilometres long set by hunters and fanned by Harmattan winds stretch along the CAR's eastern border with South Sudan while smaller agricultural fires set by farmers and pastoralists are speckled throughout the country [8,55]. This gradient is highlighted in Figure 1 using all SEVIRI active fire pixels detected between 1 October 2008 and 30 April 2009, coinciding with a single fire season [56]. Figure 1b,c illustrate that on a seasonal basis, SEVIRI generally measures more fire radiative energy (FRE) and a greater proportion of FRE during the night (19:00 to 07:00 local time) in the east of the CAR compared the west. Indeed Figure 1c reaffirms previous findings that although most fires in the CAR are lit during the day and exhibit strong diurnal cycles [1], only the fires in the east tend to burn through the night $[8,55]$. Since high measurements of FRE can be driven either by persistent fire pixels (i.e., fires that are detected within the same pixel over multiple time slots) or by high measurements of FRP, a map of the maximum FRP detected by SEVIRI in Figure 1d indicates that on an instantaneous basis, fires in the east either burn with greater reaction intensities or occupy a greater fraction of a SEVIRI pixel. The east-to-west difference in active fire area and contiguity (as illustrated in Figure 2 using two separate $500 \mathrm{~m}$ MODIS band 7 images) reaffirms previous findings that fires in the east typically have longer fire fronts than those in the west [55].

Figure 2. MODIS $2.1 \mu \mathrm{m}$ (band 7) $500 \mathrm{~m}$ spatial resolution imagery illustrating differences in typical fire behavior between the west (a) and east (b) of the CAR. Whereas individual fires in ROI 3 (a) are predominantly contained within one or two MODIS $500 \mathrm{~m}$ spatial resolution pixels, fire fronts in ROI 1 (b) quite often extend tens of kilometers.

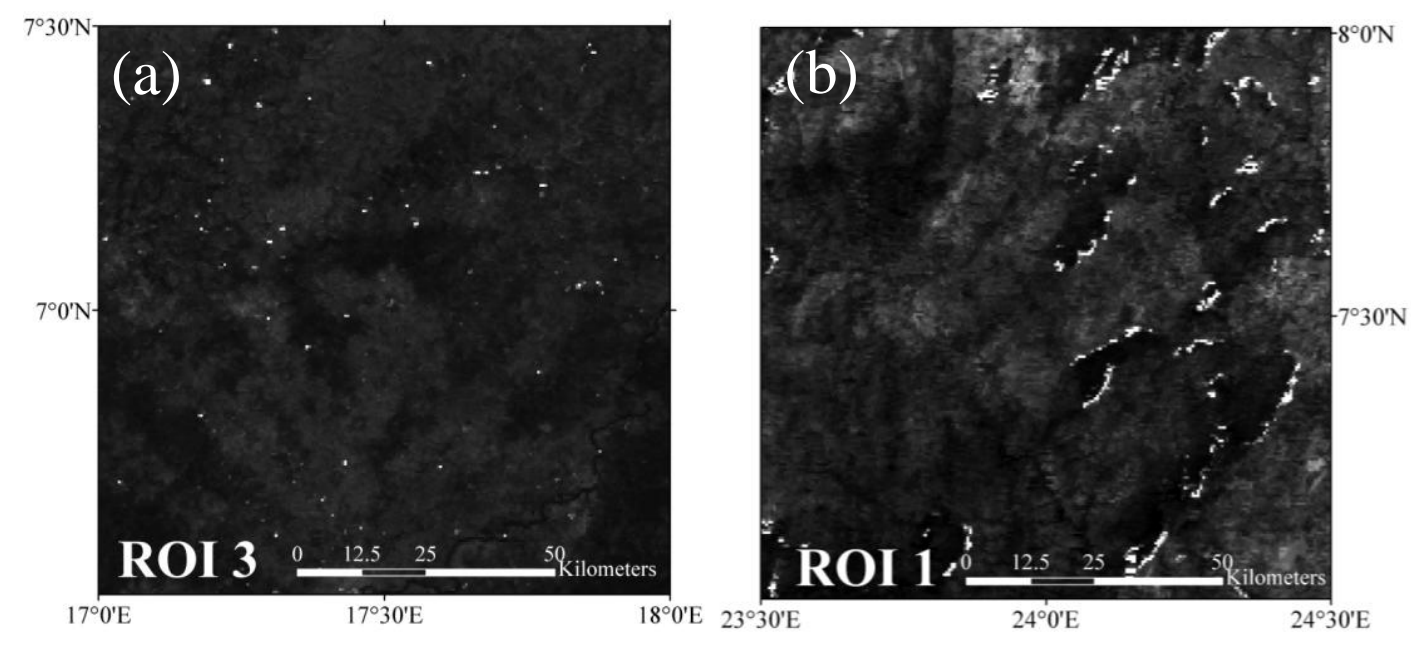


Finally but perhaps most importantly, the CAR was selected as a study site because of a long and well-documented history of satellite-based fire monitoring in the region. Rather than selecting a relatively unknown fire regime, this work leverages the understanding of fire behaviour gained from previous studies in the CAR, and references this information to substantiate our interpretations of the more recent SEVIRI and MODIS active fire products.

\section{Methods}

\subsection{Preprocessing}

To compare simultaneous SEVIRI and MODIS observations of the same fires, seven months of SEVIRI active fire pixels detected between 1 October 2008 and 30 April 2009 were clipped from the operational FRP-PIXEL product based on the timing $( \pm 8 \mathrm{~min})$ and boundaries of the MODIS Terra and Aqua granules [57]. This procedure essentially reduced SEVIRI's imaging frequency of a ground location in the CAR from 96 times per day to approximately four times per day coinciding with the repeat cycle of the MODIS ground track. In addition, the raw FRP values retrieved from the MOD/MYD14 datasets were adjusted to account for atmospheric transmittance in the MODIS $3.9 \mu \mathrm{m}$ spectral band. Similar to the LSA SAF processing of the SEVIRI active fire pixels [31], the per-pixel FRP measured by MODIS was adjusted based on $\tau_{a t m}$, which itself was calculated according to (i) the MODIS view zenith angle; and (ii) the TCWV matched to the timing and location of the MODIS active fire pixels. Although the SEVIRI-derived active fire dataset used here represents some of the earliest records in the operational FRP-PIXEL archive, the algorithms and FRP-PIXEL and MODIS active fire product versions have not changed since this time, and this date window conveniently overlaps the timing and/or area where Freeborn et al. [57,58] assimilated the same SEVIRI and MODIS active fire products. The conclusions of this study are therefore expected to be valid for the currently produced data coming from these systems.

\subsection{Identifying Regions of Interest (ROIs)}

Freeborn et al. [58] show that for cumulative observations of the same fires, the ratio of the annual sum of FRP measured by SEVIRI to that concurrently measured by MODIS is (i) always less than one; and (ii) spatially variable across Africa (see Figure 4 in Freeborn et al. [58]). Here the seasonal sum of FRP measured by SEVIRI at the MODIS overpass times was divided by that concurrently measured by MODIS to calculate a seasonal SEVIRI-to-MODIS ratio of FRP, $\phi_{\mathrm{FRP}}$, at $0.5^{\circ}$ grid cell resolution, as follows:

$$
\phi_{\mathrm{FRP}}=\frac{\sum_{i_{\text {SEVRII }}=1}^{n_{\text {SEVIRI }}} F R P_{i_{\text {SEVIRI }}}}{\sum_{i_{\text {MODIS }}=1}^{n_{\text {MODIS }}} F R P_{i_{\text {MODIS }}}}
$$

where $i_{\text {SEVIRI }}$ and $i_{\text {MODIS }}$ are concurrent active fire pixel indices for each sensor, $n_{\text {SEVIRI }}$ and $n_{\text {MODIS }}$ are the total number of concurrent active fire pixels detected by each sensor in a $0.5^{\circ}$ grid cell between 1 October 2008 and 30 April 2009, and FRP is the per-pixel fire radiative power. 
The map of $\phi_{\text {FRP }}$ at $0.5^{\circ}$ grid cell resolution (Figure 3) indicates that seasonal sums of coincident SEVIRI and MODIS measurements of FRP agree more closely in the north and east of the CAR compared to the south and west. Since on an instantaneous basis only a small bias exists between coincident SEVIRI and MODIS measurements of the FRP emitted from fire pixel clusters detected by both sensors $[17,33,59]$, we hypothesize that (i) ratios of $\phi_{\mathrm{FRP}}$ are less than one due to SEVIRI omission errors; and (ii) the spatial gradient of $\phi_{\text {FRP }}$ across the CAR is due to a coupling between the sensitivity of the SEVIRI FTA detection algorithm and a geographic variation in active fire characteristics.

In an effort to explain the geographical gradient of $\phi_{\mathrm{FRP}}$ (as shown in Figure 3), the performance of the SEVIRI FTA detection algorithm is henceforth evaluated within four $1.0^{\circ}$ regions of interest (ROIs) strategically placed across the CAR (Figures 1a and 3). The size of the ROIs was selected to capture a sufficient number of concurrent observations, and the placement of the ROIs was subjectively selected to satisfy two objectives: first, to capture the widest possible range of $\phi_{\text {FRP }}$ between the ROIs, and second, to minimize the variability of the four $0.5^{\circ}$ values of $\phi_{\mathrm{FRP}}$ within each $1.0^{\circ} \mathrm{ROI}$. Whereas the former objective is intended to sample the broadest possible range of fire behaviour and observation conditions across the CAR, the latter is intended to identify regions of relatively homogeneous fire behaviour and observation conditions. Due to SEVIRI's geostationary projection, there are 1132, 1160, 1228, and 1192 SEVIRI thermal pixels within ROIs 1, 2, 3, and 4, respectively.

Figure 3. Seasonal SEVIRI-to-MODIS ratios of summed fire radiative power (FRP) concurrently measured by both sensors, $\phi_{\mathrm{FRP}}$, mapped at $0.5^{\circ}$ grid cell resolution. The performance of the Fire Thermal Anomaly (FTA) detection algorithm is evaluated in four $1.0^{\circ}$ regions of interest (ROIs) subjectively located (i) to span the widest possible range of $\phi_{\text {FRP }}$ across the CAR; and (ii) to circumscribe relatively homogeneous values of $\phi_{\text {FRP. }}$.

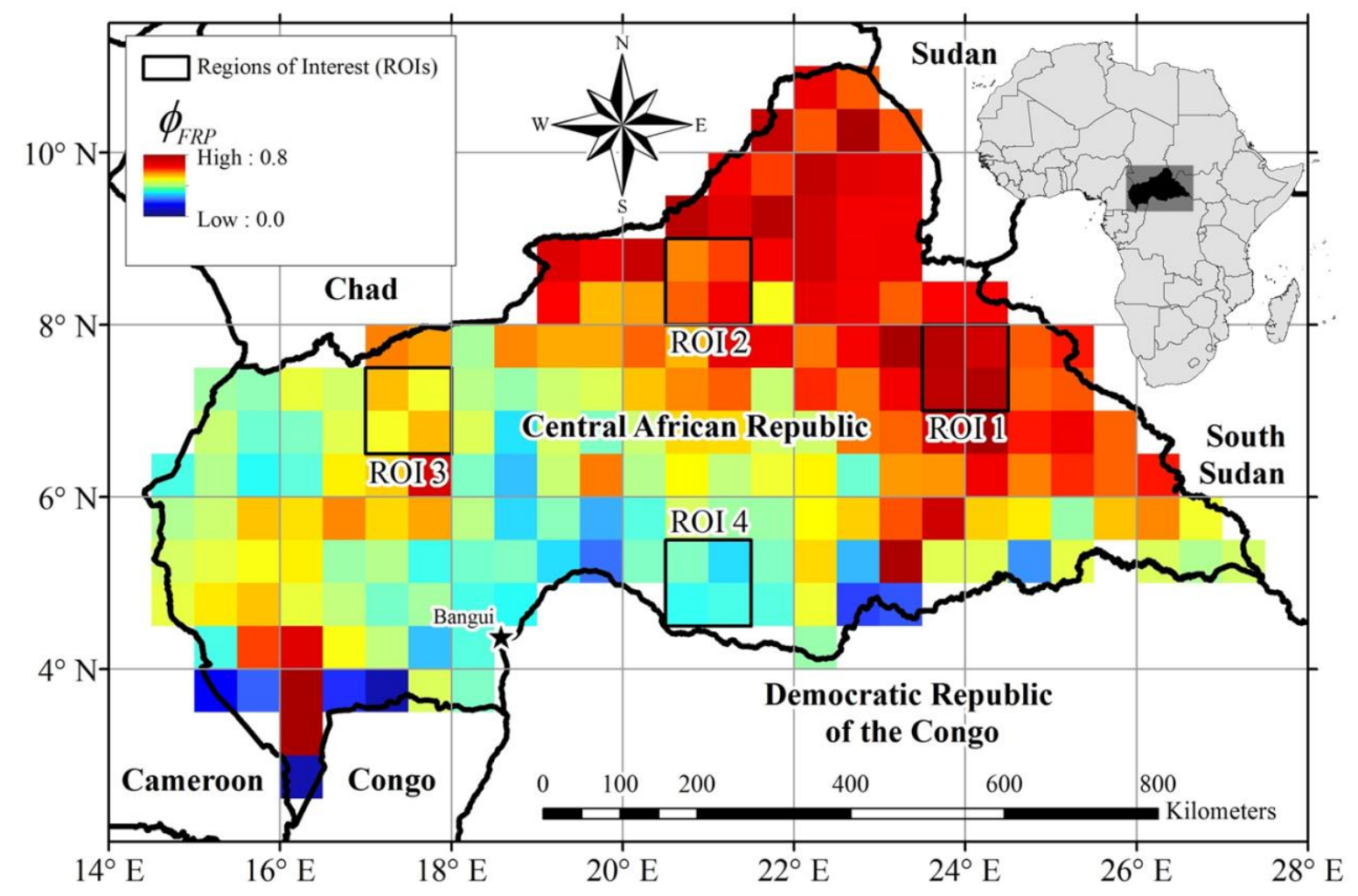




\subsection{SEVIRI Errors of Omission and Commission}

The performance of the FTA detection algorithm is evaluated in each ROI by quantifying SEVIRI's errors of omission and commission relative to MODIS. All MODIS active fire pixels (regardless of their detection confidence) were assigned to an individual SEVIRI image coordinate (i.e., column and row number) depending on whether the centre latitude and longitude of a MODIS active fire pixel fell within the ground footprint of a SEVIRI thermal pixel. SEVIRI's pixel boundaries were simply drawn at a distance halfway between adjacent SEVIRI pixel centres (Figure 4). For every concurrent observation, a record was kept of whether SEVIRI or MODIS detected a thermal anomaly at each SEVIRI image coordinate. Since the GSD of SEVIRI is coarser than MODIS at nadir, it is possible for a SEVIRI thermal pixel to contain several MODIS active fire pixels for any concurrent observation. All information about MODIS active fire pixels is preserved at each SEVIRI image coordinate.

Figure 4. SEVIRI pixel boundaries (solid and dashed lines) are drawn at a distance halfway between adjacent pixel centres (filled circles). These artificial boundaries do not coincide with the orientation and overlap of SEVIRI's point spread function (PSF), which is shown for the centre pixel located at the sub-satellite point.

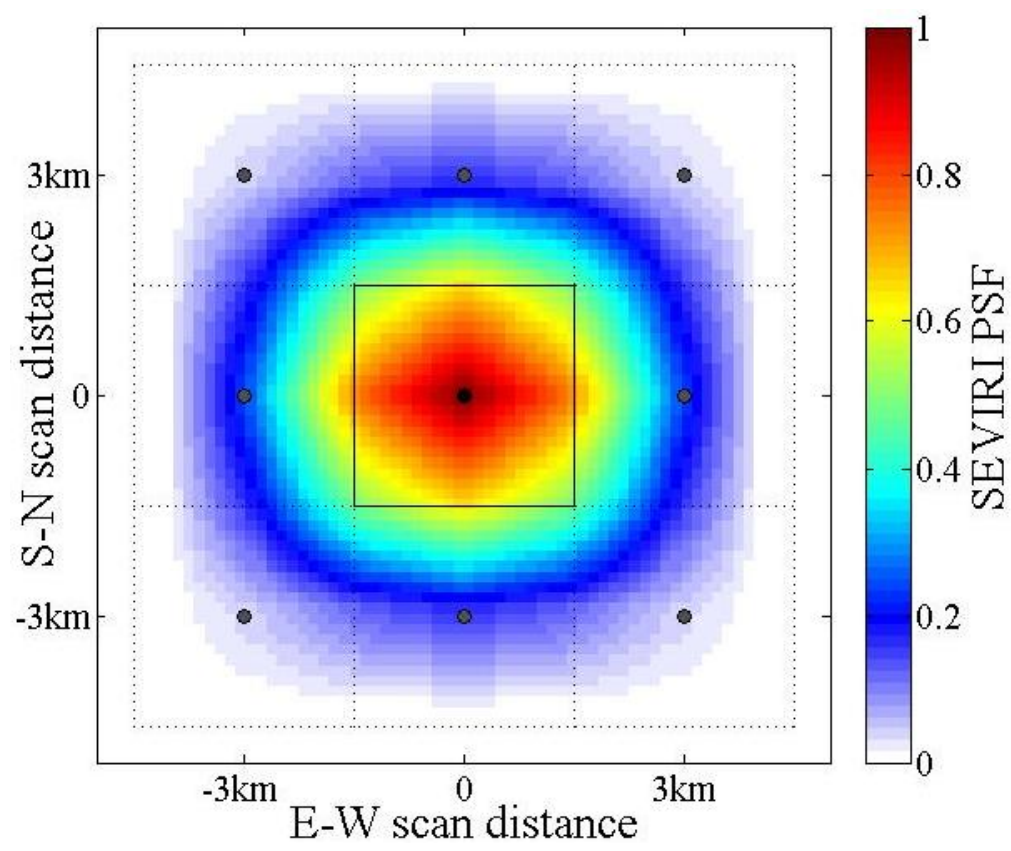

Despite its simplicity, this remapping technique remains unsatisfying due to the shape, orientation, and overlap of the IGFOV and point spread function (PSF) of both sensors. In reality, SEVIRI's detectors are diamond shaped, oriented at $45^{\circ}$ with respect to the E-W and N-S directions, and the PSF of SEVIRI at the SSP extends $\sim 5 \mathrm{~km}$ from the pixel centre [60]. Hence SEVIRI is theoretically sensitive to thermal anomalies located up to $5 \mathrm{~km}$ from the nominal pixel centre [60], and SEVIRI's active fire detection pattern may resemble a plus sign or a square ring in image space [60]. Meanwhile the focal plane layout and scanning design of MODIS induces (i) a $2 \mathrm{~km}$ triangular PSF that overlaps in the along-scan direction; and (ii) substantial scan-to-scan overlap at scan angles greater than $24^{\circ}$ [42]. Consequently it is possible for MODIS to detect the same fire in adjacent along-scan pixels [44] as well as in consecutive scans [42,57]. 
To mitigate these caveats, a $3 \times 3$ window is inspected around the target SEVIRI pixel, and SEVIRI's detection performance is evaluated based on the MODIS active fire pixels found within this $3 \times 3$ window (Figures 4 and 5). In addition, the status flags of the centre (target) SEVIRI pixel and the eight surrounding SEVIRI pixels are retrieved from the FRP-PIXEL quality file (Figure 5). Inspecting this $3 \times 3$ window crudely-but conveniently-accounts for uncertainties in (i) the geometry and overlap of the PSF of SEVIRI and MODIS; and (ii) the geolocational accuracy of both active fire products.

Figure 5. Illustration of the technique used to compare simultaneous SEVIRI and MODIS observations of the same fire activity within ROI 2 (Figure 1a) on 18 November 2008 at 09:30 UTC (shown in the native SEVIRI image coordinate system). For each SEVIRI image coordinate that contains a SEVIRI or a MODIS active fire pixel, a $3 \times 3$ window is centred on the target pixel and the adjacent SEVIRI pixels are inspected to evaluate SEVIRI's detection performance. In addition, the status flags of the SEVIRI pixels within the $3 \times 3$ window are retrieved from the FRP-PIXEL quality file and are used to explain SEVIRI's active fire errors of omission. Label (A) represents a confirmed SEVIRI active fire pixel (i.e., no omission or commission error). Label (B) highlights a SEVIRI error of omission surrounded only by cloud-free land pixels that are not potential fire pixels. Label (C) also indicates a SEVIRI error of omission, but here the error is attributed to the presence of cloud pixels. Label (D) is an example of two SEVIRI errors of commission.

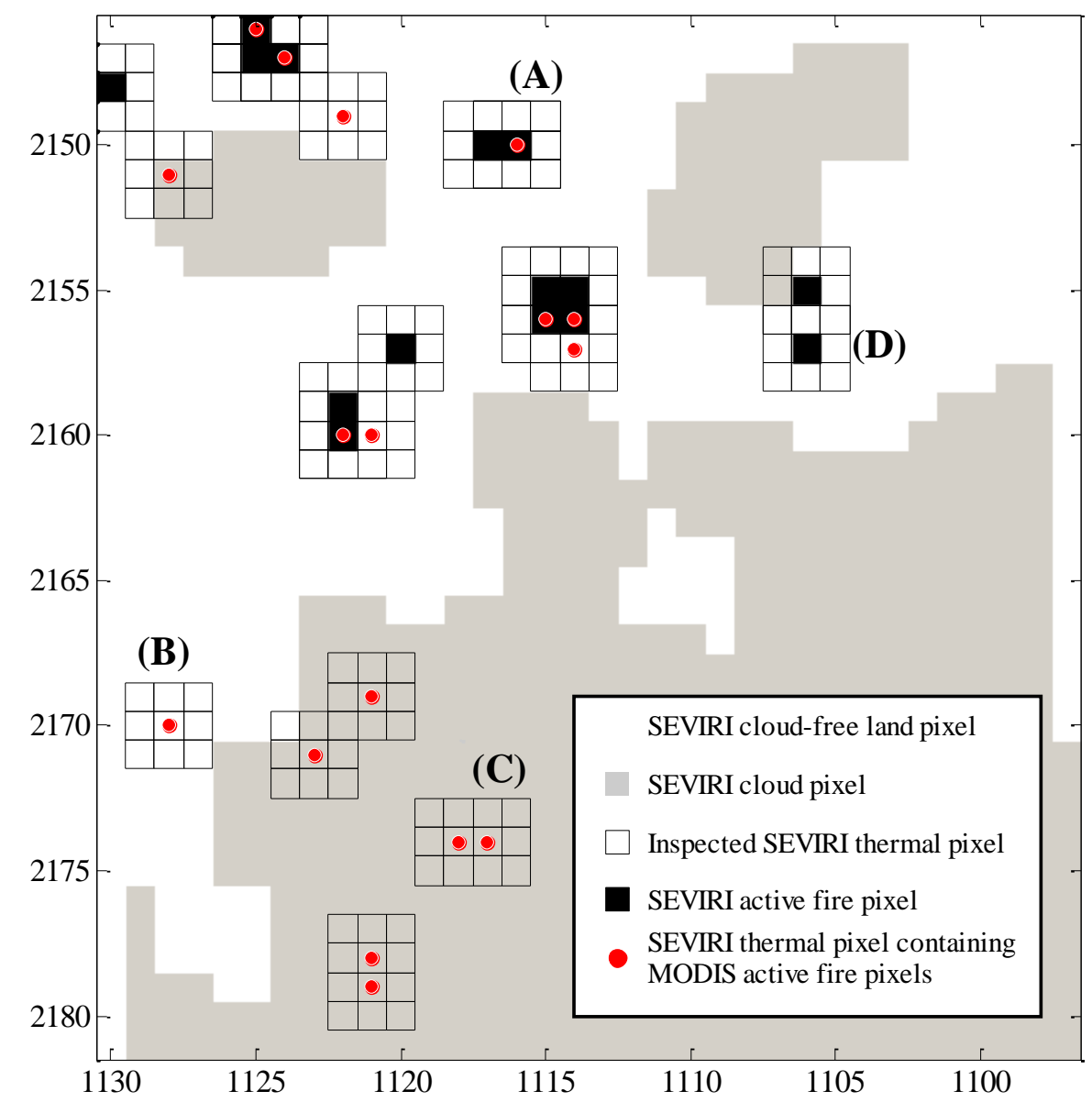


A SEVIRI active fire pixel is confirmed, and no omission or commission error is considered to occur, if a MODIS active fire pixel is found either (i) within a SEVIRI active fire pixel; or (ii) within a $3 \times 3$ window surrounding a SEVIRI active fire pixel. Such a scenario is labelled as (A) in Figure 5 . A SEVIRI omission error is considered to occur if no SEVIRI active fire pixel is found at the centre SEVIRI image coordinate containing the MODIS active fire pixel or within the $3 \times 3$ surrounding window. If the centre and the eight surrounding SEVIRI quality flags are all classified as "non-potential fire pixels", then the MODIS active fire pixel is considered to be unconditionally missed by SEVIRI. This scenario is identified as (B) in Figure 5. If, however, SEVIRI fails to detect a MODIS active fire pixel (i.e., there are no SEVIRI active fire pixels within the $3 \times 3$ surrounding window), and the processing status of any SEVIRI pixel within the $3 \times 3$ window is anything other than a "non-potential fire pixel", then the SEVIRI omission error is categorized according to the artefact that may have prevented the detection. For example, SEVIRI omission errors can be attributed to sunglint, vagaries in the background characterization, or clouds, as depicted as (C) in Figure 5. Seasonal SEVIRI omission errors in each ROI are calculated as the ratio of the number of MODIS active fire pixels not adjacent to a SEVIRI active fire pixel versus the total number of MODIS active fire pixels detected in the ROI.

For each concurrent observation, a SEVIRI active fire pixel is considered to be a commission error if no MODIS active fire pixels are found within the SEVIRI active fire pixel or within the $3 \times 3$ surrounding window, as illustrated as (D) in Figure 5. Seasonal SEVIRI commission errors are calculated in each ROI as the ratio of the number of SEVIRI active fire pixels detected in isolation (i.e., not adjacent to a MODIS active fire pixel) versus the total number of SEVIRI active fire pixels detected in the ROI.

Constructing and inspecting the $3 \times 3$ windows shown in Figures 4 and 5 is technically similar to searching for pixels within a given distance (e.g., $\mathrm{km}$ ) surrounding a SEVIRI or MODIS active fire detection. The novelty here, however, is that the search distance is "normalized" to the SEVIRI pixel dimension and therefore varies depending on the location within the Earth disk relative to the Meteosat SSP. Although we have not formally analyzed the sensitivity of SEVIRI' omission and commission rates to the size of this window, we would expect better agreement between SEVIRI and MODIS as the search window expands, e.g., see [47].

\section{Results}

A summary of the seasonal sum of FRP measured near-simultaneously by SEVIRI and MODIS is presented in Table 1. Whereas MODIS measured 3.7 times more seasonal FRP in ROI 1 than in ROI 4 (341.4 GW vs. 93.1 GW), SEVIRI measured $~ 7.6$ times more seasonal FRP in ROI 1 than in ROI 4 (256.8 GW vs. $34.0 \mathrm{GW}$ ). Hence the geographic variation in $\phi_{\mathrm{FRP}}$ (as shown in Figure 3) arises due to the fact that compared to MODIS, SEVIRI observes a much stronger gradient of fire activity across the CAR.

As part of the criteria used to subjectively locate the ROIs, values of $\phi_{\mathrm{FRP}}$ at $1.0^{\circ}$ grid cell resolution continually decrease from 0.75 in ROI 1 to 0.37 in ROI 4 (Table 1). Though not reported in Table 1 , the four $0.5^{\circ}$ values of $\phi_{\mathrm{FRP}}$ within each $1.0^{\circ}$ grid cell remain within $\pm 4 \%$ of the overall value for each 
ROI. Thus we confirm that the ROIs span a strong geographical gradient of observed fire activity, and we assume that fire behaviour and observation conditions are relatively uniform within each ROI.

Table 1. Summary of concurrent SEVIRI and MODIS active fire pixels detected in each region of interest (ROI) shown in Figure 1a between 1 October 2008 and 30 April 2009 using, respectively the SEVIRI FTA algorithm [34] and the MODIS active fire detection algorithm [38]. According to Equation (1), $\phi_{\mathrm{FRP}}$ i $\phi_{\mathrm{FRP}}$ ndicates the ratio of the seasonal sum of FRP measured by SEVIRI to that concurrently measured by MODIS.

\begin{tabular}{ccccccccc}
\hline & \multicolumn{2}{c}{ ROI 1 } & \multicolumn{2}{c}{ ROI 2 } & \multicolumn{2}{c}{ ROI 3 } & \multicolumn{2}{c}{ ROI 4 } \\
\hline & \multicolumn{2}{c}{$\phi_{\boldsymbol{F R P} P}=\mathbf{0 . 7 5}$} & \multicolumn{2}{c}{$\phi_{\boldsymbol{F R P} P}=\mathbf{0 . 6 2}$} & \multicolumn{2}{c}{$\phi_{\boldsymbol{F R P} P}=\mathbf{0 . 5 0}$} & \multicolumn{2}{c}{$\phi_{\boldsymbol{F R P}}=\mathbf{0 . 3 7}$} \\
\hline & SEVIRI & MODIS & SEVIRI & MODIS & SEVIRI & MODIS & SEVIRI & MODIS \\
\hline Sum of FRP (GW) & 256.8 & 341.4 & 164.9 & 267.4 & 72.4 & 145.6 & 34.0 & 93.1 \\
Min. FRP (MW) & 9.1 & 5.1 & 9.3 & 6.0 & 14.8 & 5.0 & 15.2 & 4.7 \\
Median FRP (MW) & 51.4 & 41.8 & 51.1 & 35.4 & 43.1 & 22.2 & 35.6 & 21.3 \\
Mean FRP (MW) & 73.0 & 73.7 & 68.7 & 61.7 & 52.4 & 35.3 & 42.7 & 32.4 \\
Max. FRP (MW) & 467.5 & 1609.3 & 429.1 & 1432.8 & 397.7 & 626.2 & 239.8 & 647.2 \\
\hline
\end{tabular}

\subsection{SEVIRI Errors of Omission and Commission}

Seasonal SEVIRI omission rates relative to MODIS increased from a minimum of $25 \%$ in ROI 1 to a maximum of $74 \%$ in ROI 4 (Table 2). By contrast, SEVIRI commission rates relative to MODIS were less variable, remaining within $\pm 8 \%$ of an overall commission rate of $24 \%$ calculated across all ROIs (Table 2). In the remainder of the results, we examine the design features of the SEVIRI and MODIS active fire detection algorithms - as well as the observation conditions - that affect sensor-to-sensor comparisons and thus the evaluation of the SEVIRI FTA detection algorithm relative to MODIS.

Table 2. Seasonal SEVIRI errors of omission and commission (shown in gray) for each region of interest (ROI) depicted in Figure 1a between 1 October 2008 and 30 April 2009. Errors of omission are decomposed into five potential reasons for the failed SEVIRI detection. Open values indicate the absolute proportion of MODIS active fire pixels missed by SEVIRI as a result of a particular artefact, and values in parentheses indicate the relative proportion of SEVIRI's omission rate in an ROI attributed to a particular artefact.

\begin{tabular}{lcccc}
\hline & ROI 1 & ROI 2 & ROI 3 & ROI 4 \\
\hline & $\phi_{F R P}=\mathbf{0 . 7 5}$ & $\phi_{F R P}=\mathbf{0 . 6 2}$ & $\phi_{F R P}=\mathbf{0 . 5 0}$ & $\phi_{F R P}=\mathbf{0 . 3 7}$ \\
\hline SEVIRI error of omission & $25 \%$ & $45 \%$ & $68 \%$ & $74 \%$ \\
$\begin{array}{l}\text { Surrounded by SEVIRI non-potential fire pixels } \\
\text { Adjacent to SEVIRI cloud or cloud edge }\end{array}$ & $4 \%(16 \%)$ & $13 \%(28 \%)$ & $26 \%(39 \%)$ & $30 \%(40 \%)$ \\
$\begin{array}{l}\text { Adjacent to SEVIRI potential fire pixel that did } \\
\text { not breach the contextual thresholds }\end{array}$ & $12 \%(49 \%)$ & $15 \%(33 \%)$ & $20 \%(30 \%)$ & $23 \%(31 \%)$ \\
$\begin{array}{l}\text { Adjacent to SEVIRI pixel without a defined } \\
\text { background temperature }\end{array}$ & $2 \%(10 \%)$ & $2 \%(4 \%)$ & $2 \%(3 \%)$ & $1 \%(1 \%)$ \\
$\begin{array}{l}\text { Adjacent to SEVIRI sunglint pixel or pixel } \\
\text { where the test for sunglint failed }\end{array}$ & $1 \%(4 \%)$ & $2 \%(4 \%)$ & $2 \%(3 \%)$ & $4 \%(5 \%)$ \\
SEVIRI error of commission & $24 \%$ & $18 \%$ & $32 \%$ & $25 \%$ \\
\hline
\end{tabular}




\subsubsection{Sunglint}

Sunglint has only a minor impact on the performance of the SEVIRI detection algorithm. Regardless of the ROI, less than $4 \%$ of the MODIS active fire pixels that SEVIRI failed to detect were located adjacent to a SEVIRI thermal pixel affected by sunglint. In relative terms, sunglint accounted for no more than 5\% of SEVIRI's omission rate in any ROI (Table 2).

\subsubsection{SEVIRI's Background Thermal Characterization}

In combination, the absence of a SEVIRI background temperature measurement and/or the failure of a potential SEVIRI fire pixel to breach the contextual background thresholds have a moderate impact on SEVIRI's active fire detection performance. Regardless of the ROI, less than $2 \%$ of the MODIS active fire pixels that SEVIRI failed to detect were located adjacent to a SEVIRI pixel without a defined background temperature, accounting for no more than $10 \%$ of SEVIRI's omission rate (Table 2). If SEVIRI did measure the background temperature, however, then between 5\% and $17 \%$ of the MODIS active fire pixels missed by SEVIRI were located adjacent to a potential SEVIRI fire pixel that could not be confirmed as a true fire pixel since its thermal signal was not sufficiently above the background. In combination, the absence of, and/or vagaries in, the background thermal characterization procedure of the SEVIRI FTA algorithm may have accounted for between $22 \%$ and $33 \%$ of SEVIRI's omission rate with respect to MODIS in any ROI.

\subsubsection{The SEVIRI and MODIS Cloud Masks}

The cloud mask used during the processing of the FRP-PIXEL product has a substantial impact on the performance of the SEVIRI FTA detection algorithm, confounding no less than $30 \%$ of SEVIRI's omission rate in any ROI. Given the weight of this finding, we compared the SEVIRI and MODIS cloud masks used during the generation of both active fire products. The MODIS cloud cover fraction,

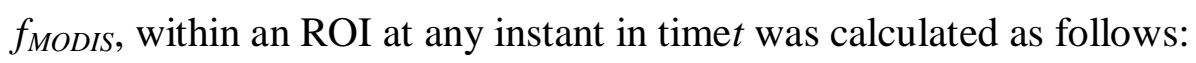

$$
f_{\text {MODIS }}(t)=\frac{N_{\text {cloud }}(t)}{N_{\text {total }}(t)}
$$

where $N_{\text {cloud }}(t)$ is the number of MODIS cloud pixels observed in the ROI at time $t$, and $N_{\text {total }}(t)$ is the total number of MODIS pixels covering the ROI at time $t$. Note that $N_{\text {total }}(t)$ for MODIS varies with $t$ depending on the MODIS viewing geometry. For comparison, an analogous version of Equation (2) was also used to calculate the SEVIRI cloud cover fraction, $f_{\text {SEVIRI }}$, within $\pm 8 \mathrm{~min}$ of time $t$. Note that due to SEVIRI's geostationary projection, the number of SEVIRI thermal pixels in each ROI does not change over time.

Figure 6a,b illustrate that $f_{\text {SEVIRI }}$ is greater than $f_{M O D I S}$ for $99 \%$ of the near-simultaneous observations. In one poignant example, the cloud mask used during the generation of the SEVIRI FRP-PIXEL product classified ROI 1 as $91 \%$ cloudy at the same time the cloud mask used during the generation of the MODIS fire product classified ROI 1 as $1 \%$ cloudy (Figure 7). This discrepancy is attributed to a high, thin layer of cirrus that was classified as clouds by SEVIRI in the FRP-PIXEL quality file, but was ignored by MODIS in the MYD14 fire mask. Neither is necessarily incorrect, but 
rather the definition of what constitutes a "cloudy pixel" differs between the detection algorithms. We re-visit this topic in more detail in Section 6.

Figure 6. Comparisons between the internal cloud mask used during the processing of the MODIS active fire products and the SAFNWC cloud mask used during processing of the SEVIRI FRP-PIXEL product. In (a) are 1139 concurrent observations of the instantaneous cloud cover fraction in each ROI shown in Figure 1a, calculated for MODIS, $f_{M O D I S}$, and SEVIRI, $f_{\text {SEVIRI }}$ (see Equation (2)). Observations in (a) are aggregated over all ROIs and sorted into $10 \%$ bins of $f_{M O D I S}$, as shown in (b).
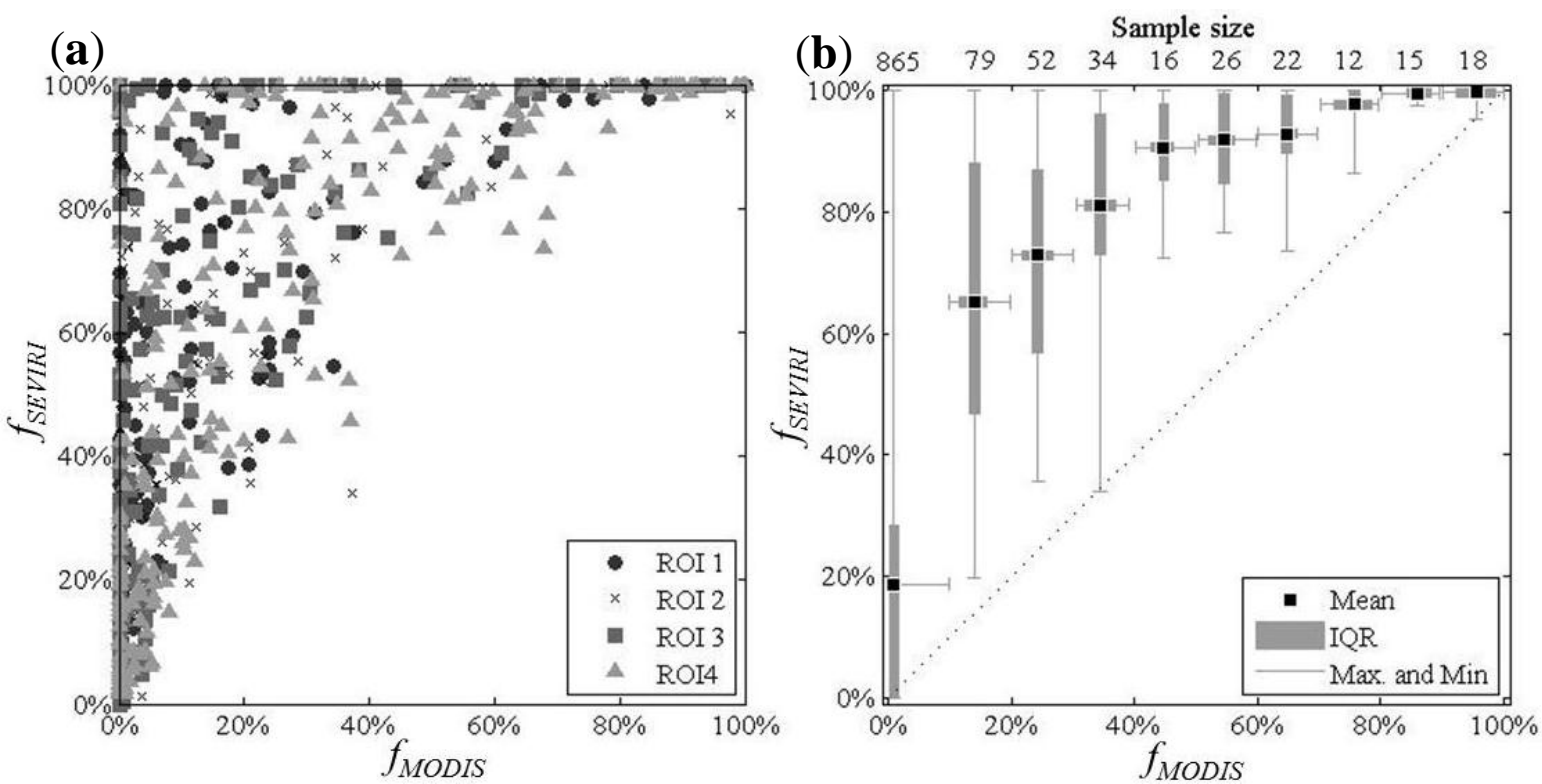

\subsubsection{SEVIRI's Low Spatial Resolution Detection Bias}

The proportion of MODIS active fire pixels that SEVIRI failed to detect and were completely surrounded by SEVIRI non-potential fire pixels (i.e., cloud-free land pixels) continually increased from $4 \%$ in ROI $1 \%$ to $30 \%$ in ROI 4 (Table 2). Thus in the absence of confounding artefacts, SEVIRI unconditionally missed more MODIS active fire pixels in the south and west of the CAR compared to the north and east. Without an alternative explanation for the failed detections, these statistics (more than any other presented here) demonstrate (i) the isolated impact of SEVIRI's low spatial resolution detection bias; and (ii) a geographic variability in SEVIRI's active fire detection performance. Depending on the location in the CAR, between $16 \%$ and $40 \%$ of SEVIRI's omission rate is attributable to a low spatial resolution detection bias.

In the absence of confounding artefacts, the probability that SEVIRI will detect a fire depends on a combination of the reaction intensity and the instantaneous area of the subpixel combustion components. Although it is possible to retrieve the effective temperature and area of a subpixel fire using either a "dual-band" algorithm [61] or a multi-spectral analysis (e.g., [62]), these approaches were not attempted here due to the potentially large uncertainties in the retrieval of these parameters [63]. Instead two basic remote sensing parameters were used to infer differences in fire behaviour across the CAR: 
i. Coherent with an increase in SEVIRI's omission rate, the median, mean, and maximum FRP measured by both MODIS and SEVIRI continually decreased from ROI 1 to ROI 4 (Table 1). The distributions of FRP used to derive the MODIS statistics are shown in Figure 8a.

ii. An independent clustering of MODIS active fire pixels demonstrates that coherent with an increase in SEVIRI's omission rate, the cluster size of contiguous active fire pixels decreases from ROI 1 to ROI 4 (Figure 8b). Whilst the maximum cluster size progressively decreased from 29 active fire pixels in ROI 1 to six in ROI 4, solitary MODIS active fire pixels accounted for $29 \%$ of the clusters in ROI 1 and nearly $60 \%$ in ROI 4.

Hence we find that regional variations in the performance of the SEVIRI FTA detection algorithm coincide with a geographical gradient in observed active fire characteristics.

Figure 7. Simultaneous comparisons between the cloud masks used in the MODIS and SEVIRI active fire products at 12:00 UTC on 11 January 2009 within ROI 1 (Figure 1a). The $500 \mathrm{~m}$ MODIS Aqua true colour image is presented in (a); the MODIS fire mask retrieved from the coincident MYD14 fire product is presented in (b); the status flags retrieved from the coincident SEVIRI FRP-PIXEL quality file are shown in (c); and the MODIS cloud mask retrieved from the coincident MYD35 cloud product is shown in (d). Aside from the true colour image (which has been reprojected into geographic coordinates), the masks are shown in their native image coordinate system along with the boundary of ROI 1 .
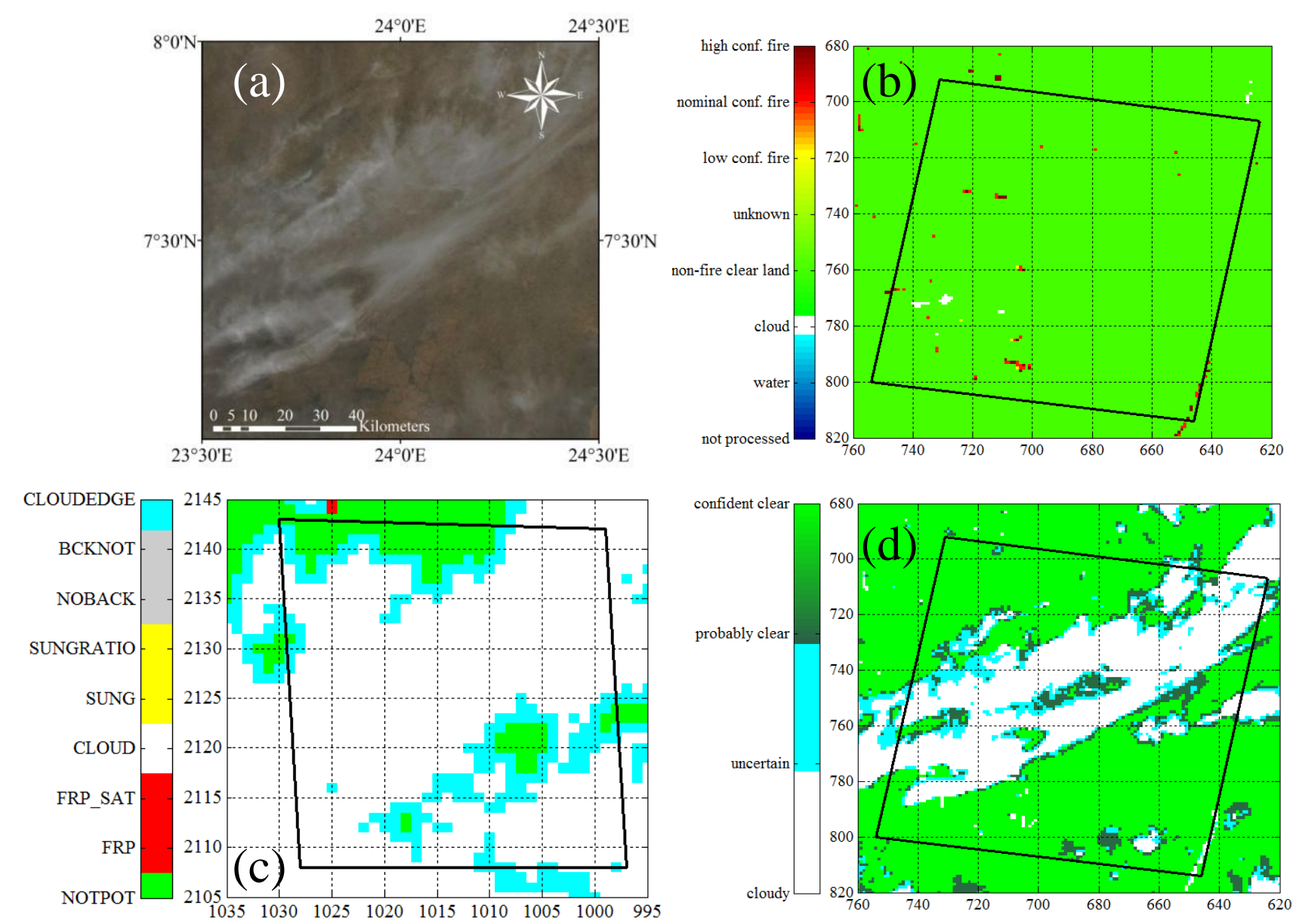
Figure 8. (a) Histogram of the per-pixel fire radiative power (FRP) measured by MODIS in each of the four ROIs depicted in Figure 1a between 1 October 2008 and 31 April 2009. A shift in the distributions from high FRP pixels to low FRP pixels between ROI 1 and ROI 4 is coherent with an increase in SEVIRI's omission rate. (b) Histogram of the cluster size of MODIS active fire pixels in each of the four ROIs between 1 October 2008 and 31 April 2009. A shift in the distribution from larger to smaller cluster sizes between ROI 1 and ROI 4 is also coherent with an increase in SEVIRI's omission rate.
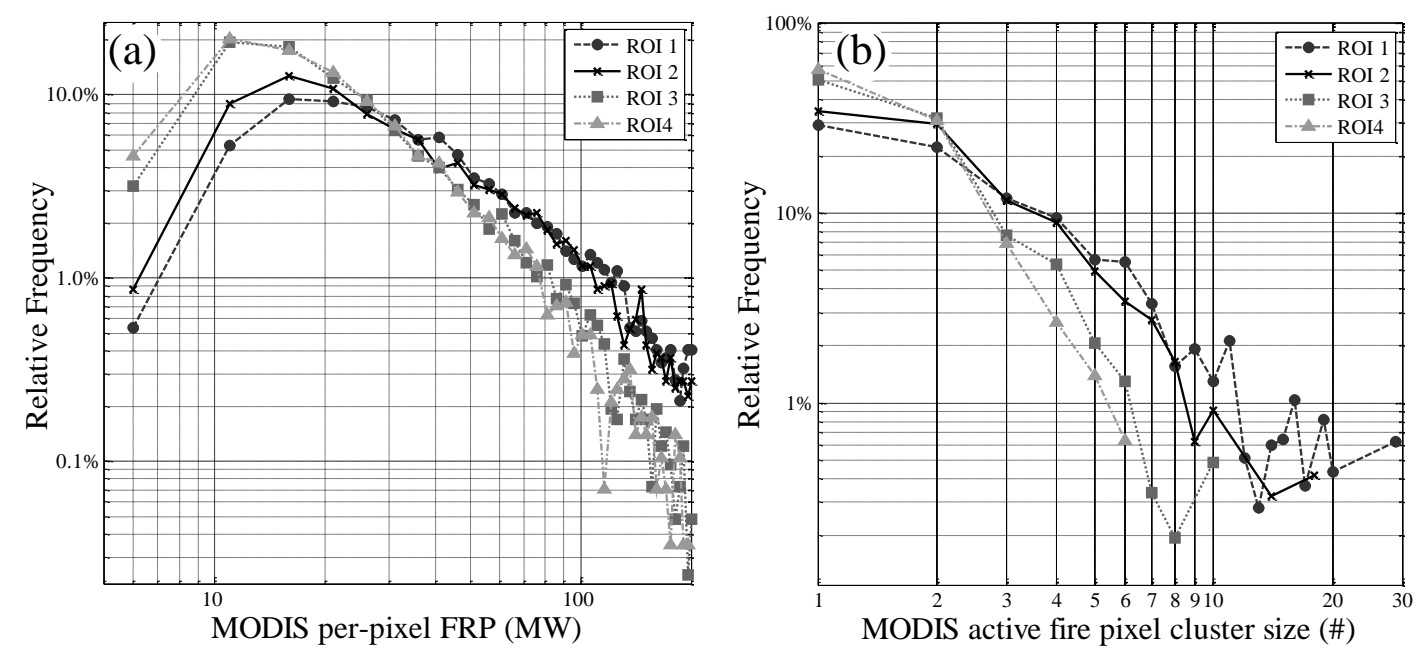

\subsection{SEVIRI's Detection Performance Stratified by Land Cover and Tree Cover}

It is possible to argue that fire behaviour could be homogeneous across the CAR, and that other non-fire factors are influencing geographic variations in the SEVIRI and MODIS observations of fire activity. Whilst we cannot account for all spatial variables, we stratified SEVIRI's omission rate and MODIS measurements of FRP by land cover using the Global Land Cover 2000 (GLC2000) database [64], and also by percent tree cover using the Global Land Cover Facility (GLCF) Version 3 of the Collection 4 Vegetation Continuous Field (VCF) product [65].

Despite stratifying active fire pixels into GLC2000 classes, differences in SEVIRI's omission rate were found between the ROIs even within the same land cover class (Table 3). Meaningful results are limited here to the "Deciduous woodland" since this class occupies $83 \%$ of all ROIs, varying from $100 \%$ in ROI $1 \%$ to $67 \%$ in ROI 4. SEVIRI's omission rate in the "Deciduous woodland" ranged from a minimum of $25 \%$ in ROI 1 to a maximum of $72 \%$ in ROI 4 , and coherent with SEVIRI's omission rate, the median FRP measured by MODIS in the "Deciduous woodland" decreased from $41.8 \mathrm{MW}$ in ROI 1 to 21.8 MW in ROI 4 (Table 3).

SEVIRI's detection performance in the "Deciduous woodland" was further decomposed based on percent tree cover. Distributions of VCF percent tree cover in the "Deciduous woodland" (degraded to $\sim 3 \mathrm{~km}$ resolution) are shown for each ROI in Figure 9a. Note that 93\% of all SEVIRI active fire pixels detected in the "Deciduous woodland" were found under $20 \%-50 \%$ tree cover. SEVIRI's omission rate under this range of tree cover remained relatively constant within each ROI, but differed between the ROIs (Figure 9b). In addition, Figure 9c demonstrates that the median FRP measured by MODIS under 20\%-50\% tree cover in the "Deciduous woodland" remained relatively constant within each ROI ( \pm 6 MW), but differed between the ROIs. 
Table 3. Seasonal SEVIRI errors of omission within each region of interest (ROI) depicted in Figure 1a between 1 October 2008 and 30 April 2009 stratified according to the Global Land Cover (GLC2000) database [64].

\begin{tabular}{|c|c|c|c|c|c|c|c|c|c|c|c|c|}
\hline & & ROI 1 & & & ROI 2 & & & ROI 3 & & & ROI 4 & \\
\hline & & $\phi_{F R P}=0.75$ & & & $\phi_{F R P}=0.62$ & & & $\phi_{F R P}=0.50$ & & & $\phi_{F R P}=0.37$ & \\
\hline $\begin{array}{l}\text { (GLC2000) } \\
\text { Global land } \\
\text { Cover } \\
\text { classification }\end{array}$ & $\begin{array}{c}\text { Area } \\
\text { Covered }\end{array}$ & $\begin{array}{c}\text { SEVIRI } \\
\text { Omission } \\
\text { Rate }\end{array}$ & $\begin{array}{c}\text { Median } \\
\text { MODIS } \\
\text { FRP } \\
\text { (MW) }\end{array}$ & $\begin{array}{c}\text { Area } \\
\text { Covered }\end{array}$ & $\begin{array}{c}\text { SEVIRI } \\
\text { Omission } \\
\text { Rate }\end{array}$ & $\begin{array}{c}\text { Median } \\
\text { MODIS } \\
\text { FRP } \\
\text { (MW) }\end{array}$ & $\begin{array}{c}\text { Area } \\
\text { Covered }\end{array}$ & $\begin{array}{c}\text { SEVIRI } \\
\text { Omission } \\
\text { Rate }\end{array}$ & $\begin{array}{c}\text { Median } \\
\text { MODIS } \\
\text { FRP } \\
\text { (MW) }\end{array}$ & $\begin{array}{c}\text { Area } \\
\text { Covered }\end{array}$ & $\begin{array}{c}\text { SEVIRI } \\
\text { Omission } \\
\text { Rate }\end{array}$ & $\begin{array}{c}\text { Median } \\
\text { MODIS } \\
\text { FRP } \\
\text { (MW) }\end{array}$ \\
\hline $\begin{array}{l}\text { (1) Closed } \\
\text { evergreen } \\
\text { lowland forest }\end{array}$ & - & - & - & $2 \%$ & $73 \%$ & 28.1 & - & - & - & $3 \%$ & $92 \%$ & 17.7 \\
\hline $\begin{array}{l}\text { (8) Mosaic } \\
\text { forest- } \\
\text { savannah }\end{array}$ & - & - & - & $6 \%$ & $42 \%$ & 44.8 & $10 \%$ & $89 \%$ & 13.5 & $30 \%$ & $79 \%$ & 18.7 \\
\hline $\begin{array}{l}\text { (10) } \\
\text { Deciduous } \\
\text { woodland }\end{array}$ & $100 \%$ & $25 \%$ & 41.8 & $76 \%$ & $49 \%$ & 32.4 & $89 \%$ & $68 \%$ & 22.8 & $67 \%$ & $72 \%$ & 21.8 \\
\hline $\begin{array}{l}\text { (11) } \\
\text { Deciduous } \\
\text { shrubland with } \\
\text { sparse trees }\end{array}$ & - & - & - & $16 \%$ & $30 \%$ & 50.6 & $1 \%$ & $68 \%$ & 24.4 & - & - & - \\
\hline
\end{tabular}

Figure 9. SEVIRI's detection performance and MODIS' measurements of FRP in the "Deciduous woodland" landcover class [64] stratified by vegetation continuous fields (VCF) percent tree cover [65]. Distributions of $500 \mathrm{~m} \mathrm{VCF}$ percent tree cover in the "Deciduous woodland" degraded to $3 \mathrm{~km}$ resolution are shown in (a). SEVIRI's active fire errors of omission as a function of percent tree cover in "Deciduous woodland" are shown in (b). Note that numbers in (b) represent the count of SEVIRI thermal pixels used to calculate SEVIRI's omission rate, and that 93\% of SEVIRI active fire pixels were detected under 20\%-50\% tree cover (shaded). The median FRP measured by MODIS in "Deciduous woodland" is presented as a function of tree cover in (c).
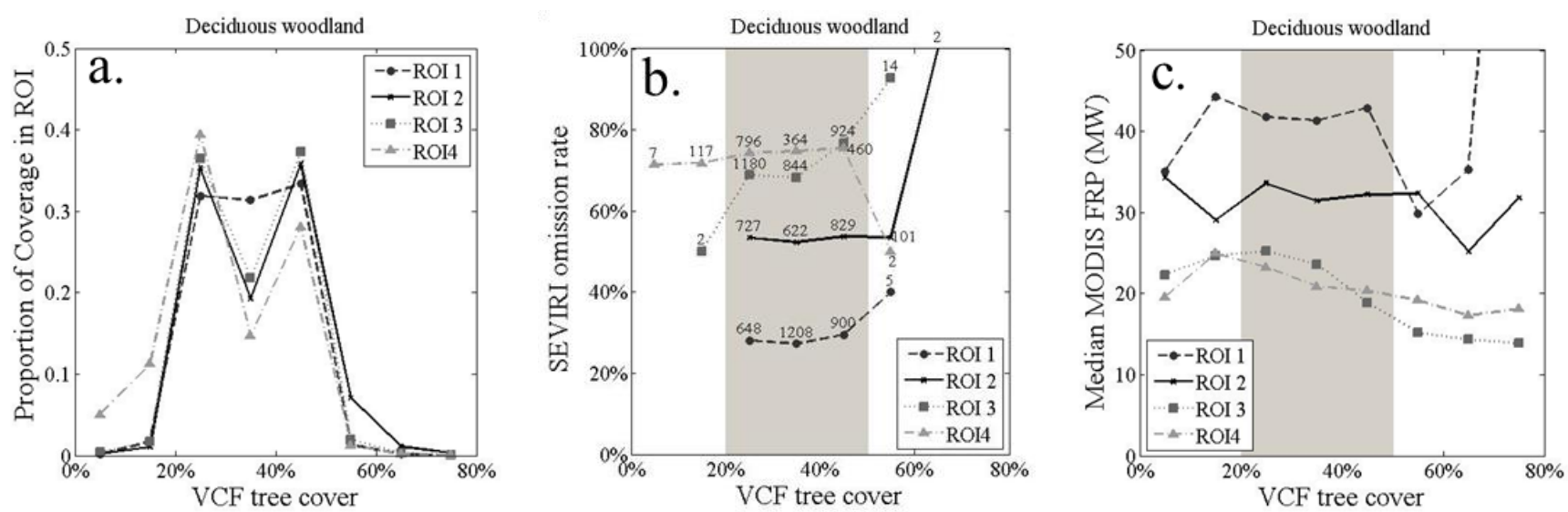
Based on this evidence we suggest that it is possible for SEVIRI's detection performance and MODIS measurements of FRP to vary substantially within similar vegetation types and canopy structures across the CAR, indicating that spatial variations in vegetation characteristics are not the primary cause of variations in the FTA detection performance with respect to MODIS.

\subsection{Impacts of Viewing Geometry on SEVIRI's Detection Performance}

The sub-pixel fraction occupied by a fire (and thus the probability of detecting a fire) decreases as pixel area increases with increasing scan angle [66]. Therefore the combination of SEVIRI and MODIS viewing geometries will inevitably affect the evaluation of SEVIRI's detection performance - particularly at extreme MODIS scan angles where nominal SEVIRI and MODIS pixel areas are nearly equivalent in the CAR.

SEVIRI's errors of omission and commission presented in Table 2 were calculated without regard to scan angle. Although SEVIRI view zenith angles in ROI 1 are greater than in ROI 3 (corresponding to larger ground footprints), SEVIRI's omission rate is considerably lower in ROI 1 than in ROI 3. Since larger SEVIRI pixels would imply greater errors of omission, this contradiction suggests that other factors besides SEVIRI's view zenith angle (e.g., active fire characteristics) have a greater influence on SEVIRI's active fire detection performance across the CAR.

Independent of the ROI in which fire pixels were detected, Figure 10a demonstrates that the evaluation of SEVIRI's omission rate depends on MODIS scan angle. The decrease in SEVIRI's omission rate as a function of MODIS scan angle is attributed to the decreased ability of MODIS to detect low FRP pixels towards the scene edges [57,67]. After accounting for atmospheric transmissivity, the minimum FRP measured by SEVIRI in all ROIs was 9.1 MW (Table 1). For comparison, MODIS measured no less than $\sim 10 \mathrm{MW}$ for fire pixels detected in all ROIs above a scan angle of $33^{\circ}$ (Figure 10b). Although the minimum detection limit of MODIS at the swath edges ( $\sim 50 \mathrm{MW})$ is well above SEVIRI's minimum detection limit, SEVIRI's omission rate evaluated at MODIS scan angles above of $50^{\circ}$ does not completely drop to zero, but instead only decreases to $\sim 18 \%$. Upon closer examination, the majority ( $89 \%$ ) of SEVIRI's errors of omission located at the MODIS swath edges were confounded by sunglint, uncertainties in the background characterization, or cloud cover.

The rise in the commission rate of the SEVIRI FTA detection algorithm towards the MODIS scene edges (Figure 10a) is also attributed to an increase in the MODIS active fire omission rate away from nadir. Since SEVIRI is able to detect active fire pixels with an FRP less than the MODIS minimum limit of $\sim 50 \mathrm{MW}$ at the swath edges, it is quite possible that SEVIRI errors of commission at extreme MODIS scan angles may not be false alarms, but rather true fires that MODIS failed to detect due to the increased pixel size at the MODIS scene edges.

To report a more genuine estimate of SEVIRI's true active fire detection performance, sensor-to-sensor comparisons were limited to MODIS scan angles within $\pm 18.3^{\circ}$ of nadir (i.e., within $\pm 235 \mathrm{~km}$ of MODIS nadir). Within this central portion of the MODIS swath, where the MODIS active fire detection performance has been well characterised using co-incident ASTER observations [16,44-46], SEVIRI's omission and commission rates in ROIs 1, 2, 3, and 4 were recalculated as $34 \%, 52 \%, 70 \%$, and $82 \%$, and $4 \%, 11 \%, 14 \%$, and $10 \%$, respectively. If accumulated over all ROIs, then SEVIRI's overall omission and commission rates in the CAR evaluated near MODIS nadir were 59\% and 9\%, 
respectively, which agree quite well with previously reported monthly values ranging between $54 \%-57 \%$ and $6 \%-8 \%$, respectively [33].

Figure 10. In (a) are seasonal SEVIRI errors of omission and commission evaluated for all regions of interest (ROIs) as a function of MODIS scan angle. In (b) is the minimum atmospherically corrected FRP detected by MODIS over all ROIs as a function of MODIS scan angle.
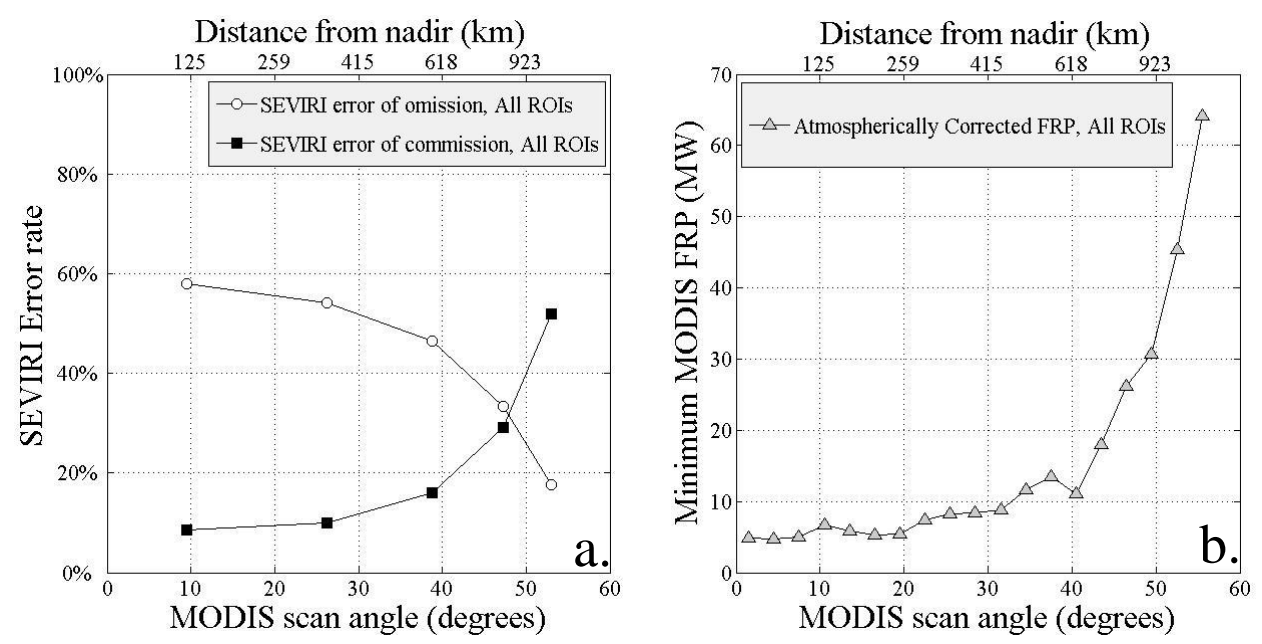

\subsection{Verification of the Seasonal Radiative Energy Budget}

Here we examine our assumptions that (i) SEVIRI and MODIS measure the same FRP emitted from simultaneously detected fires; and (ii) that sensor-to-sensor differences in the seasonal radiative energy budgets (see Table 1 and Figure 3) are attributed to SEVIRI omission errors. Instantaneous comparisons between SEVIRI and MODIS measurements of FRP were strictly limited to clusters of contiguous active fire pixels surrounded only by SEVIRI "non-potential fire pixels" (i.e., cloud-free land pixels), referred to hereafter as "well observed fires". The correlation between SEVIRI and MODIS ( $R^{2}=0.61$ for $n=282$ clusters over all ROIs) shown in Figure 11a is slightly lower than that reported by Roberts et al. [17], but a bias of $-14.2 \mathrm{MW}$ (calculated as the mean difference between all observations) and a scatter of 290.4 MW (calculated as the standard deviation of the differences between all observations) agrees quite well with Roberts et al. [17].

Figure 11b, however, indicates that for well observed fires, SEVIRI does not universally measure less FRP than MODIS. Despite the scatter, SEVIRI tends to measure more FRP than MODIS for low FRP clusters and less FRP than MODIS for high FRP clusters. If comparisons of well-observed fires are limited to MODIS measurements of FRP between $40 \mathrm{MW}$ and $3000 \mathrm{MW}$ then the bias and the scatter reduce to $-1.3 \mathrm{MW}$ and 212.0 MW, respectively-agreeing quite well with the analysis and results of Roberts and Wooster [33].

A low bias indicates that for aggregations of numerous, simultaneous observations over the entire fire season, and over all ROIs, SEVIRI and MODIS measure on average the same FRP emitted from well observed fires. Interestingly, however, Figure $11 \mathrm{~b}$ suggests that SEVIRI's overestimation of MODIS at low MODIS measurements of FRP tends to balance out SEVIRI's underestimation of MODIS at high MODIS measurements of FRP. Indeed we find that the summed FRP measured by 
SEVIRI over all well observed active fire pixel clusters detected in all ROI's during the fire season agrees within $\pm 5 \%$ of that measured by MODIS. Therefore we quantitatively confirm our assumptions and reaffirm the assertion of Roberts et al. [17] that for concurrent and collocated observations, differences between the regional and seasonal radiant heat budgets measured by SEVIRI and MODIS are attributed to SEVIRI omission errors.

Figure 11. Comparison between the fire radiative power (FRP) emitted from well-observed fire pixel clusters simultaneously detected by SEVIRI and MODIS. All clusters are completely surrounded by SEVIRI "non-potential fire pixels". In (a) is the direct relationship, and in (b) is the ratio of the FRP measured by SEVIRI to that measured by MODIS, $\phi_{\mathrm{FRP}}$, on a cluster basis and sorted by the number of SEVIRI active fire pixels detected in each cluster. Note: SEVIRI clusters with $>5$ active fire pixels are not included in (b).

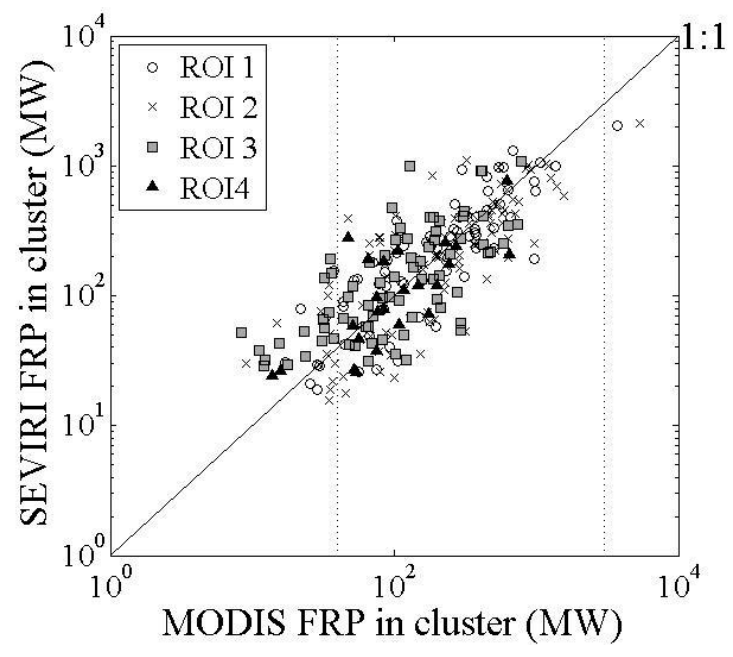

(a)

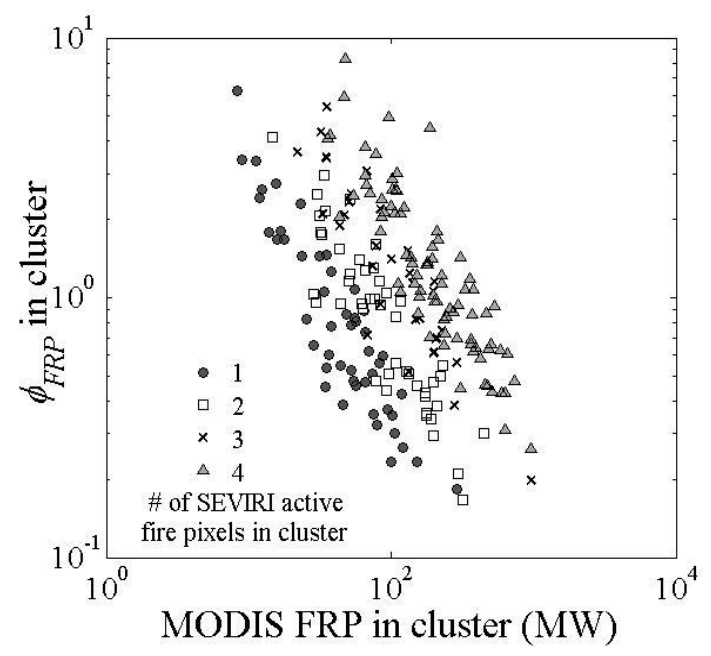

(b)

\subsection{SEVIRI's Daily Omission Rate}

Omission rates presented in Table 2 indicate the ability of SEVIRI to detect active fires in the same location and at the exact same time as MODIS. A similar routine was used here instead to assess the ability of SEVIRI to detect fires at the same location and on the same day as MODIS. Re-evaluating SEVIRI's active fire detection performance on a daily basis (i.e., using all 96 SEVIRI observations and all four MODIS observations per day) revealed that SEVIRI's daily omission rate in ROIs 1, 2, 3, and 4 decreases to $3 \%, 12 \%, 31 \%$ and $41 \%$, respectively. These results quantitatively affirm that although SEVIRI may fail to detect a fire concurrent with a MODIS overpass, at some time during the day the observation conditions may improve or the same fire may become powerful enough to trigger the FTA detection algorithm.

\section{Conclusions}

This work has used the MODIS active fire product to quantitatively asses the performance of the FTA active fire detection algorithm used to generate the Meteosat SEVIRI FRP-PIXEL fire product. Though comparisons were performed across a strong gradient of fire activity in the Central African 
Republic (CAR), such gradients are not uncommon in northern Africa, e.g., in Senegal [68]. Therefore rather than selecting validation sites across global variations in fire regimes, we suggest that steep geographical gradients in fire behavior may offer more localized opportunities to evaluate the active fire detection performance of SEVIRI and/or other satellite-based sensors.

Many tests are used by the FTA algorithm to discriminate SEVIRI pixels containing active fires whilst minimizing false alarms [38]. Mistakenly classifying sunglint as an active fire is an important issue that active fire detection algorithms must avoid by judicious use of multispectral tests (e.g., [38,69]). Although it is possible for such tests to also occasionally remove "true" fire pixels, we found sunglint to have a minor impact on SEVIRI's active fire detection performance. Instead, the FTA detection algorithms performance was more influenced by the absence of and/or uncertainties in the estimated background temperature surrounding potential fire pixels, a key parameter required for establishing the contextual thresholds used when confirming an active fire pixel as a true fire pixel [33]. Although it may be possible to design regional contextual detection thresholds (e.g., [70]), this practice potentially results in higher commission (i.e., false alarm) rates. Moreover, the current FTA detection algorithm is already capable of identifying active fire pixels with MIR brightness temperatures only a few Kelvin above that of the background, so the detection criteria are likely already being pushed to their limits. Thus the scope for further refining the contextual detection criteria in the FTA algorithm with the aim of detecting a greater number of active fires appears rather limited.

Results here also indicate that the performance of the SEVIRI FTA detection algorithm is strongly affected by the cloud mask, accounting for no less than $30 \%$ of SEVIRI's active fire omission rate when compared to MODIS. The cloud mask used during the processing of the SEVIRI FRP-PIXEL product is generated every $15 \mathrm{~min}$ by the SAF to support NoWcasting and Very Short-Range Forecasting, SAFNWC [71]. The SAFNWC cloud mask explicitly aims to detect all types of clouds, with the goal of confidently identifying SEVIRI observations of the land surface uncontaminated by cloud [71]. In contrast, the tailored cloud detection algorithm used during the generation of the MODIS fire products is designed specifically for the active fire application to distinguish only larger, cooler, and optically thick clouds, and sacrifices the ability to discern thin cirrus and cloud edges in favour of reducing the possibility of misclassifying fire-affected pixels as cloudy [38,39]. Other SEVIRI active fire detection algorithms have implemented different cloud detection strategies (e.g., [48,72]), and refinement of the cloud mask used for in the FRP-PIXEL product maybe warranted, though it should not be inferred that SEVIRI's omission rate relative to MODIS would decrease if an alternative cloud mask were used. Instead we simply agree with the suggestions of Calle et al. [72] that the performance of any SEVIRI active fire detection algorithm would very likely benefit from a custom cloud mask designed specifically for active fire detection applications.

Our results have demonstrated quantitatively that the performance of satellite-based active fire detection algorithms varies with geographical variations in active fire characteristics. Moreover, we found that SEVIRI's detection performance and MODIS active fire characteristics varied across the CAR even in the same land cover and percent tree cover, suggesting that it is possible for substantial differences in fire behaviour to occur within similar vegetation types and canopy structures found in the CAR. We concede, however, that SEVIRI's ground footprint subtends a distribution of landcover and percent tree cover such that the values of these parameters used to stratify SEVIRI and MODIS active fire pixels may not adequately represent the full nature of the landscape characteristics. 
Due to an increase in the MODIS' active fire omission rate away from nadir [57], the evaluation of the SEVIRI FTA detection algorithm depended on MODIS scan angle. Our results strongly suggest that viewing geometries must be taken into account if SEVIRI and MODIS observations are to be properly assimilated (e.g., [73]).

We confirm a minimal bias between simultaneous SEVIRI and MODIS measurements of FRP of the same fire clusters, indicating that when both sensors detect the same fire they provide similar measurements of FRP. Hence we reaffirm the assertion of Roberts et al. [17] that sensor-to-sensor differences in regional/seasonal energy budgets are attributed to SEVIRI omission errors, specifically the fact that SEVIRI fails to detect many of the low FRP pixels that MODIS, by virtue of its smaller pixel area at nadir, can in theory detect. Results here further agree with Roberts et al. [17] and Roberts and Wooster [33] in so far as SEVIRI tends to measure more FRP than MODIS for low FRP active fire pixel clusters, and less FRP than MODIS for high FRP active fire pixel clusters. Without speculating on the reasons for this relationship, such behavior was also noticed in comparisons between MODIS and the Geostationary Operational Environmental Satellite (GOES) imager ([74]; Figure 2 therein).

Since SEVIRI's active fire detection performance varies geographically due to spatial variations in active fire characteristics, and given that fire behavior fluctuates over the course of a day and over the course of a season, it can be inferred that SEVIRI's active fire detection performance also varies diurnally and seasonally. Although the coarse spatial resolution of geostationary images imposes a lower limit on the size and intensity (and thus FRP) of a detectable fire [17,48,72], we find that the numerous observations per day afforded by SEVIRI can be utilized as a detection strategy, ultimately reducing omission rates when evaluated on a daily basis. Therefore we suggest that future work examine the cumulative impact of SEVIRI's instantaneous active fire detection performance on the characterization of longer term fire regime parameters, such annual fire occurrence and seasonality.

Overall this work has contributed significantly to the understanding of the performance of the SEVIRI FTA detection algorithm implemented at the LSA SAF to generate the operational Meteosat SEVIRI FRP-PIXEL product. It is expected that results herein will provide direction and focus for further improvements to the FTA detection algorithm. We also suggest that this work has important implications if SEVIRI observations are to be used to fill gaps between MODIS overpasses, or if SEVIRI is considered for inclusion into a network of geostationary satellites designed to achieve global diurnal active fire monitoring.

\section{Acknowledgments}

The authors would like to thank three anonymous reviewers for their time and for providing very useful comments. P.H.F. was funded through a King's College London (SSPP) studentship award, and M.J.W. is funded by the UK National Centre for Earth Observation. This work is performed within the framework of the Land Surface Analysis Satellite Applications Facility [36], which is funded by EUMETSAT and from where the SEVIRI FRP-Pixel products are made available to users. NASA is kindly acknowledged for their free access to MODIS data, and the LSA SAF and EUMETSAT are thanked for free provision of the SEVIRI datasets used herein. 


\section{Author Contributions}

Patrick H. Freeborn designed the study, analyzed the data, and wrote the manuscript. Martin J. Wooster, Gareth Roberts and Weidong Xu contributed to the study design and to the writing of the manuscript.

\section{Conflicts of Interest}

The authors declare no conflict of interest.

\section{References}

1. Moula, M.; Brustet, J.; Fontan, J. Remote sensing-modelisation approach for diurnal estimation of burnt biomass in the Central African Republic savanna. J. Atmos. Chem. 1996, 25, 1-19.

2. Langaas, S. Temporal and spatial distribution of savanna fires in Senegal and the Gambia, West Africa, 1989-90, derived from multi-temporal AVHRR night images. Int. J. Wildland Fire 1992, 2, 21-36.

3. Trollope, W.S.W.; de Ronde, C.; Geldenhuys, C.J. Fire Behaviour. In Wildland Fire Management Handbook for Sub-Sahara Africa; Goldammer, J.G., de Ronde, C., Eds.; Global Fire Monitoring Center and Oneworldbooks: Freiburg-Cape Town, South Africa, 2004; pp. $27-55$.

4. Malingreau, J.P. The Contribution of Remote Sensing to the Global Monitoring of Fires in Tropical and Subtropical Ecosystems. In Fire in the Tropical Biota, Ecosystem Processes and Global Challenges; Goldammer, J.G., Ed.; Springer-Verlag: Berlin, Germany, 1990; pp. 337-369.

5. Justice, C.O.; Korontzi, S. A Review of the Status of Satellite fire Monitoring and the Requirements for Global Environmental Change Research. In Global and Regional Vegetation Fire Monitoring from Space: Planning a Coordinated International Effort; Ahern, F.J., Goldammer, J.G., Justice, C.O., Eds.; SPB Academic Publishing: New York, NY, USA, 2001; pp. 1-18.

6. Kennedy, P. Biomass burning studies: The use of remote sensing. Ecol. Bull. 1992, 42, 133-148.

7. Justice, C.O.; Malingreau, J.-P.; Setzer, A.W. Satellite Remote Sensing of Fires: Potential and Limitations. In Fire in the Environment: The Ecological, Atmospheric, and Climatic Importance of Vegetation Fires; Crutzen, P.J., Goldammer, J.G., Eds.; John Wiley \& Sons Ltd.: New York, NY, USA, 1993; pp. 77-88.

8. Eva, H.; Lambin, E.F. Remote sensing of biomass burning in tropical regions: Sampling issues and multisensor approach. Remote Sens. Environ. 1998, 64, 292-315.

9. Giglio, L. Characterization of the tropical diurnal fire cycle using VIRS and MODIS observations. Remote Sens. Environ. 2007, 108, 407-421.

10. Vermote, E.; Ellicott, E.; Dubovik, O.; Lapyonok, T.; Chin, M.; Giglio, L.; Roberts, G. An approach to estimate global biomass burning emissions of organic and black carbon from MODIS fire radiative power. J. Geophys. Res. Atmos. 2009, 114, doi:10.1029/2008JD011188.

11. Ellicott, E.; Vermote, E.; Giglio, L.; Roberts, G. Estimating biomass consumed from fire using MODIS FRE. Geophys. Res. Lett. 2009, 36, doi:10.1029/2009GL038581. 
12. Hyer, E.J.; Reid, J.S.; Prins, E.M.; Hoffman, J.P.; Schmidt, C.C.; Miettinen, J.I.; Giglio, L. Patterns of fire activity over Indonesia and Malaysia from polar and geostationary satellite observations. Atmos. Res. 2013, 122, 504-519.

13. Prins, E.; Menzel, W. Geostationary satellite detection of biomass burning in South America. Int. J. Remote Sens. 1992, 13, 2783-2799.

14. Prins, E.; Feltz, J.; Menzel, W.; Ward, D. An overview of GOES-8 diurnal fire and smoke results for SCAR-B and 1995 fire season in South America. J. Geophys. Res. Atmos. 1998, 103, 31821-31835.

15. Roberts, G.; Wooster, M.; Lagoudakis, E. Annual and diurnal African biomass burning temporal dynamics. Biogeosciences 2009, 6, 849-866.

16. Schroeder, W.; Prins, E.; Giglio, L.; Csiszar, I.; Schmidt, C.; Morisette, J.; Morton, D. Validation of GOES and MODIS active fire detection products using ASTER and ETM plus data. Remote Sens. Environ. 2008, 112, 2711-2726.

17. Roberts, G.; Wooster, M.; Perry, G.; Drake, N.; Rebelo, L.; Dipotso, F. Retrieval of biomass combustion rates and totals from fire radiative power observations: Application to southern Africa using geostationary SEVIRI imagery. J. Geophys. Res. Atmos. 2005, 110, doi:10.1029/2005JD006018.

18. Schroeder, W.; Csiszar, I.; Morisette, J. Quantifying the impact of cloud obscuration on remote sensing of active fires in the Brazilian Amazon. Remote Sens. Environ. 2008, 112, 456-470.

19. Mu, M.; Randerson, J.T.; van der Werf, G.R.; Giglio, L.; Kasibhatla, P.; Morton, D.; Collatz, G.J.; DeFries, R.S.; Hyer, E.J.; Prins, E.M.; et al. Daily and 3-hourly variability in global fire emissions and consequences for atmospheric model predictions of carbon monoxide. J. Geophys. Res. Atmos. 2011, 116, doi:10.1029/2011JD016245.

20. Zhang, X.Y.; Kondragunta, S. Temporal and spatial variability in biomass burned areas across the USA derived from the GOES fire product. Remote Sens. Environ. 2008, 112, 2886-2897.

21. Zhang, X.Y.; Kondragunta, S.; Ram, J.; Schmidt, C.; Huang, H.C. Near-real-time global biomass burning emissions product from geostationary satellite constellation. J. Geophys. Res. Atmos. 2012, 117, doi:10.1029/2012JD017459.

22. Zhang, X.Y.; Kondragunta, S.; Schmidt, C.; Kogan, F. Near real time monitoring of biomass burning particulate emissions (PM2.5) across contiguous United States using multiple satellite instruments. Atmos. Environ. 2008, 42, 6959-6972.

23. Freitas, S.R.; Longo, K.M.; Chatfield, R.; Latham, D.; Dias, M.A.F.S.; Andreae, M.O.; Prins, E.; Santos, J.C.; Gielow, R.; Carvalho, J.A. Including the sub-grid scale plume rise of vegetation fires in low resolution atmospheric transport models. Atmos. Chem. Phys. 2007, 7, 3385-3398.

24. Sofiev, M.; Vankevich, R.; Ermakova, T.; Hakkarainen, J. Global mapping of maximum emission heights and resulting vertical profiles of wildfire emissions. Atmos. Chem. Phys. 2013, 13, 7039-7052.

25. Wang, J.; Christopher, S.A.; Nair, U.S.; Reid, J.S.; Prins, E.M.; Szykman, J.; Hand, J.L. Mesoscale modeling of Central American smoke transport to the United States: 1. "Top-down" assessment of emission strength and diurnal variation impacts. J. Geophys. Res. Atmos. 2006, 111, doi:10.1029/2005JD006416. 
26. Reid, J.S.; Hyer, E.J.; Prins, E.M.; Westphal, D.L.; Zhang, J.L.; Wang, J.; Christopher, S.A.; Curtis, C.A.; Schmidt, C.C.; Eleuterio, D.P.; et al. Global monitoring and forecasting of biomass-burning smoke: Description of and lessons from the fire locating and modeling of burning emissions (FLAMBE) program. IEEE J. Sel. Top. Appl. Earth Obs. Remote Sens. 2009, 2 , 144-162.

27. Cahoon, D.R.; Stocks, B.J.; Levine, J.S.; Cofer, W.R.; Oneill, K.P. Seasonal distribution of African savanna fires. Nature 1992, 359, 812-815.

28. Langaas, S. Diurnal cycles in savanna fires. Nature 1993, 363, doi:10.1038/363120b0.

29. Generoso, S.; Breon, F.; Balkanski, Y.; Boucher, O.; Schulz, M. Improving the seasonal cycle and interannual variations of biomass burning aerosol sources. Atmos. Chem. Phys. 2003, 3, 1211-1222.

30. Giglio, L.; Kendall, J.D. Commentary on "Improving the seasonal cycle and interannual variations of biomass burning aerosol sources" by Generoso et al. Atmos. Chem. Phys. 2004, 4, $585-587$.

31. Govaerts, Y.; Wooster, M.; Freeborn, P.; Lattanzio, A.; Roberts, G. Algorithm Theoretical Basis Document for the MSG SEVIRI Fire Radiative Power (FRP) Characterization: FRP Version 2.6; EUMETSAT, 2010. Available online: http://landsaf.meteo.pt/algorithms.jsp?seltab=12\&starttab=12 (accessed on 27 February 2014).

32. Lattanzio, A.; Govaerts, Y. Product User Manual: PUM FRP Fire Radiative Power, 2010; p. 46. Available online: http://landsaf.meteo.pt/algorithms.jsp?seltab=12\&starttab=12 (accessed on 27 February 2014).

33. Roberts, G.; Wooster, M. Fire detection and fire characterization over Africa using Meteosat SEVIRI. IEEE Trans. Geosci. Remote Sens. 2008, 46, 1200-1218.

34. Wooster, M.; Zhukov, B.; Oertel, D. Fire radiative energy for quantitative study of biomass burning: Derivation from the BIRD experimental satellite and comparison to MODIS fire products. Remote Sens. Environ. 2003, 86, 83-107.

35. Wooster, M.; Roberts, G.; Perry, G.; Kaufman, Y. Retrieval of biomass combustion rates and totals from fire radiative power observations: FRP derivation and calibration relationships between biomass consumption and fire radiative energy release. J. Geophys. Res.: Atmos. 2005, 110, doi:10.1029/2005JD006318.

36. Available online: http://landsaf.meteo.pt/algorithms.jsp?seltab=12\&starttab=12 (accessed on 27 February 2014).

37. Giglio, L. MODIS Collection 5 Active Fire Product User's Guide: Version 2.5; Department of Geographical Sciences, University of Maryland: College Park, MD, USA, 2013. Available online: https://earthdata.nasa.gov/sites/default/files/field/document/MODIS_Fire_Users_Guide_2.5.pdf (accessed on 27 February 2014).

38. Giglio, L.; Descloitres, J.; Justice, C.; Kaufman, Y. An enhanced contextual fire detection algorithm for MODIS. Remote Sens. Environ. 2003, 87, 273-282.

39. Justice, C.; Giglio, L.; Korontzi, S.; Owens, J.; Morisette, J.; Roy, D.; Descloitres, J.; Alleaume, S.; Petitcolin, F.; Kaufman, Y. The MODIS fire products. Remote Sens. Environ. 2002, 83, 244-262.

40. Kaufman, Y.; Justice, C.; Flynn, L.; Kendall, J.; Prins, E.; Giglio, L.; Ward, D.; Menzel, W.; Setzer, A. Potential global fire monitoring from EOS-MODIS. J. Geophys. Res. Atmos. 1998, 103, 32215-32238. 
41. Kaufman, Y.; Hobbs, P.; Kirchhoff, V.; Artaxo, P.; Remer, L.; Holben, B.; King, M.; Ward, D.; Prins, E.; Longo, K.; et al. Smoke, clouds, and radiation-Brazil (SCAR-B) experiment. J. Geophys. Res. Atmos. 1998, 103, 31783-31808.

42. Wolfe, R.E.; Nishihama, M.; Fleig, A.J.; Kuyper, J.A.; Roy, D.P.; Storey, J.C.; Patt, F.S. Achieving sub-pixel geolocation accuracy in support of MODIS land science. Remote Sens. Environ. 2002, 83, 31-49.

43. Available online: http://reverb.echo.nasa.gov/reverb/ (accessed on 27 February 2014).

44. Morisette, J.; Giglio, L.; Csiszar, I.; Setzer, A.; Schroeder, W.; Morton, D.; Justice, C. Validation of MODIS active fire detection products derived from two algorithms. Earth Interact. 2005, 9, 1-25.

45. Morisette, J.; Giglio, L.; Csiszar, I.; Justice, C. Validation of the MODIS active fire product over Southern Africa with ASTER data. Int. J. Remote Sens. 2005, 26, 4239-4264.

46. Csiszar, I.; Morisette, J.; Giglio, L. Validation of active fire detection from moderate-resolution satellite sensors: The MODIS example in northern Eurasia. IEEE Trans. Geosci. Remote Sens. 2006, 44, 1757-1764.

47. Calle, A.; Gonzalez-Alonso, F.; de Miguel, S. Validation of active forest fires detected by MSG-SEVIRI by means of MODIS hot spots and AWiFS images. Int. J. Remote Sens. 2008, 29, 3407-3415.

48. Amraoui, M.; DaCamara, C.; Pereira, J. Detection and monitoring of African vegetation fires using MSG-SEVIRI imagery. Remote Sens. Environ. 2010, 114, 1038-1052.

49. Prins, E.; Schmetz, J.; Flynn, L.; Hillger, D.; Feltz, J. Overview of Current and Future Diurnal Active Fire Monitoring Using a Suite of International Geostationary Satellites. In Global and Regional Wildfire Monitoring: Current Status and Future Plans; Ahern, F.J., Goldammer, J.G., Justice, C.O., Eds.; SPB Academic Publishing: The Hague, The Netherlands, 2001; pp. 145-170.

50. Rasmussen, K.; Russell-Smith, J.; Morisette, J.T. Establishing Validation Site Network for Remote Sensing Applications to Fire Research: A Joint Activity between GOFC-Fire and the LPV Subgroup; GOFC-Fire Implementation Team and the CEOS WGCV Land Product Validation Subgroup, 2001. Available online: http://lpvs.gsfc.nasa.gov/PDF/GOFC_LPV_fire_sites.pdf (accessed on 27 February 2014).

51. Giglio, L.; Randerson, J.; van der Werf, G.; Kasibhatla, P.; Collatz, G.; Morton, D.; DeFries, R. Assessing variability and long-term trends in burned area by merging multiple satellite fire products. Biogeosciences 2010, 7, 1171-1186.

52. Van der Werf, G.; Randerson, J.; Giglio, L.; Collatz, G.; Mu, M.; Kasibhatla, P.; Morton, D.; DeFries, R.; Jin, Y.; van Leeuwen, T. Global fire emissions and the contribution of deforestation, savanna, forest, agricultural, and peat fires (1997-2009). Atmos. Chem. Phys. 2010, 10, 11707-11735.

53. Nielsen, T. Characterization of fire regimes in the Experiment for Regional Sources and Sinks of Oxidants (EXPRESSO) study Area. J. Geophys. Res.: Atmos. 1999, 104, 30713-30723.

54. Dwyer, E.; Pereira, J.; Gregoire, J.; DaCamara, C. Characterization of the spatio-temporal patterns of global fire activity using satellite imagery for the period April 1992 to March 1993. J. Biogeogr. 2000, 27, 57-69.

55. Eva, H.; Flasse, S. Contextual and multiple-threshold algorithms for regional active fire detection with AVHRR data. Remote Sens. Rev. 1996, 14, 333-351. 
56. Koffi, B.; Gregoire, J.M.; Mahe, G.; Lacaux, J.P. Remote-sensing of bush fire dynamics in central-Africa from 1984 to 1988 - Analysis in relation to regional vegetation and pluviometric patterns. Atmos. Res. 1995, 39, 179-200.

57. Freeborn, P.; Wooster, M.; Roberts, G. Addressing the spatiotemporal sampling design of MODIS to provide estimates of the fire radiative energy emitted from Africa. Remote Sens. Environ. 2011, $115,475-489$.

58. Freeborn, P.; Wooster, M.; Roberts, G.; Malamud, B.; Xu, W. Development of a virtual active fire product for Africa through a synthesis of geostationary and polar orbiting satellite data. Remote Sens. Environ. 2009, 113, 1700-1711.

59. Roberts, G.; Wooster, M.; Freeborn, P.; Xu, W. Integration of geostationary FRP and polar-orbiter burned area datasets for an enhanced biomass burning inventory. Remote Sens. Environ. 2011, 115, 2047-2061.

60. Calle, A.; Casanova, J.; Gonzalez-Alonso, F. Impact of point spread function of MSG-SEVIRI on active fire detection. Int. J. Remote Sens. 2009, 30, 4567-4579.

61. Dozier, J. A method for satellite identification of surface temperature fields of subpixel resolution. Remote Sens. Environ. 1981, 11, 221-229.

62. Dennison, P.; Matheson, D. Comparison of fire temperature and fractional area modeled from SWIR, MIR, and TIR multispectral and SWIR hyperspectral airborne data. Remote Sens. Environ. 2011, 115, 876-886.

63. Giglio, L.; Kendall, J. Application of the Dozier retrieval to wildfire characterization-A sensitivity analysis. Remote Sens. Environ. 2001, 77, 34-49.

64. Mayaux, P.; Bartholome, E.; Fritz, S.; Belward, A. A new land-cover map of Africa for the year 2000. J. Biogeogr. 2004, 31, 861-877.

65. Hansen, M.; DeFries, R.; Townshend, J.; Carroll, M.; Dimiceli, C.; Sohlberg, R. Global percent tree cover at a spatial resolution of 500 meters: First results of the MODIS vegetation continuous fields algorithm. Earth Interact. 2003, 7, 1-15.

66. Giglio, L.; Kendall, J. Evaluation of global fire detection algorithms using simulated AVHRR infrared data. Int. J. Remote Sens. 1999, 20, 1947-1985.

67. Kumar, S.; Roy, D.; Boschetti, L.; Kremens, R. Exploiting the power law distribution properties of satellite fire radiative power retrievals: A method to estimate fire radiative energy and biomass burned from sparse satellite observations. J. Geophys. Res. Atmos. 2011, 116, doi:10.1029/2011JD015676.

68. Mbow, C.; Nielsen, T.T.; Rasmussen, K. Savanna fires in east-central Senegal: Distribution patterns, resource management and perceptions. Hum. Ecol. 2000, 28, 561-583.

69. Wooster, M.J.; Xu, W.; Nightingale, T. Sentinel-3 SLSTR active fire detection and FRP product: Pre-launch algorithm development and performance evaluation using MODIS and ASTER datasets. Remote Sens. Environ. 2012, 120, 236-254.

70. Seielstad, C.A.; Riddering, J.P.; Brown, S.R.; Queen, L.P.; Hao, W.M. Testing the sensitivity of a MODIS-like daytime active fire detection model in Alaska using NOAA/AVHRR infrared data. Photogramm. Eng. Remote Sens. 2002, 68, 831-838.

71. Derrien, M.; le Gleau, H. MSG/SEVIRI cloud mask and type from SAFNWC. Int. J. Remote Sens. 2005, 26, 4707-4732. 
72. Calle, A.; Casanova, J.; Romo, A. Fire detection and monitoring using MSG spinning enhanced visible and infrared imager (SEVIRI) data. J. Geophys. Res. Biogeosci. 2006, 111, doi:10.1029/2005JG000116.

73. Kaiser, J.W.; Heil, A.; Andreae, M.O.; Benedetti, A.; Chubarova, N.; Jones, L.; Morcrette, J.J.; Razinger, M.; Schultz, M.G.; Suttie, M.; et al. Biomass burning emissions estimated with a global fire assimilation system based on observed fire radiative power. Biogeosciences 2012, 9, 527-554.

74. Schroeder, W.; Csiszar, I.; Giglio, L.; Schmidt, C. On the use of fire radiative power, area, and temperature estimates to characterize biomass burning via moderate to coarse spatial resolution remote sensing data in the Brazilian Amazon. J. Geophys. Res.: Atmos. 2010, 115, doi:10.1029/2009JD013769.

(C) 2014 by the authors; licensee MDPI, Basel, Switzerland. This article is an open access article distributed under the terms and conditions of the Creative Commons Attribution license (http://creativecommons.org/licenses/by/3.0/). 